\title{
Review
}

\section{Dissociating Normal Aging from Alzheimer's Disease: A View from Cognitive Neuroscience}

\author{
Max Toepper ${ }^{\mathrm{a}, \mathrm{b}, *}$ \\ ${ }^{a}$ Department of Psychiatry and Psychotherapy Bethel, Research Division, \\ Evangelisches Krankenhaus Bielefeld (EvKB), Bielefeld, Germany \\ ${ }^{\mathrm{b}}$ Department of Psychiatry and Psychotherapy Bethel, Department of Geriatric Psychiatry, \\ Evangelisches Krankenhaus Bielefeld (EvKB), Bielefeld, Germany
}

Accepted 23 January 2017

\begin{abstract}
Both normal aging and Alzheimer's disease (AD) are associated with changes in cognition, grey and white matter volume, white matter integrity, neural activation, functional connectivity, and neurotransmission. Obviously, all of these changes are more pronounced in $\mathrm{AD}$ and proceed faster providing the basis for an $\mathrm{AD}$ diagnosis. Since these differences are quantitative, however, it was hypothesized that $\mathrm{AD}$ might simply reflect an accelerated aging process. The present article highlights the different neurocognitive changes associated with normal aging and $\mathrm{AD}$ and shows that, next to quantitative differences, there are multiple qualitative differences as well. These differences comprise different neurocognitive dissociations as different cognitive deficit profiles, different weights of grey and white matter atrophy, and different gradients of structural decline. These qualitative differences clearly indicate that $\mathrm{AD}$ cannot be simply described as accelerated aging process but on the contrary represents a solid entity.
\end{abstract}

Keywords: Activation, aging, Alzheimer's disease, atrophy, cognition, connectivity, fractional anisotropy, mean diffusivity, structural integrity, volume

\section{NEUROCOGNITIVE CHANGES ASSOCIATED WITH NORMAL AGING}

\section{Age-related changes in cognition}

Both normal aging and Alzheimer's disease (AD) are associated with changes in cognition. Obviously, these changes are more pronounced in $\mathrm{AD}$ and pro-

\footnotetext{
*Correspondence to: Dr. Max Toepper, Evangelisches Krankenhaus Bielefeld (EvKB), Klinik für Psychiatrie und Psychotherapie Bethel, Haus Gilead IV, Forschungsabteilung, Dr. Max Toepper, Remterweg 69-71, D-33617 Bielefeld, Germany. Tel.: +49 521 77278521; Fax: +49 521 77278511; E-mail: max.toepper@evkb.de.
}

ceed faster providing the basis for an $\mathrm{AD}$ diagnosis. Nevertheless, age-related cognitive changes can also be observed in healthy individuals $[1,2]$. These changes do not involve all cognitive domains but particularly relate to executive and attentional functions. Semantic and verbal knowledge, by contrast, appear to be relatively preserved from age-related change $[1,3]$. Executive and attentional dysfunctions may affect various subdomains such as cognitive flexibility, reasoning, focused and divided attention, and processing speed [1, 3-13]. Noteworthy, agerelated memory dysfunctions are reported as well, including impaired short-term memory, episodic long-term memory, and working memory [1], the 
latter of which is associated with numerous of the mentioned subfunctions per definition. The working memory model of Baddeley [14-17], for example, assumes a central executive component controlling and coordinating certain subsystems by the allocation of available attentional resources. The working memory model of Cowan [18] considers working memory as a temporally activated part of long-term memory. Cowan's model also postulates a central executive component directing the focus of attention by the allocation of resources. Information that gets into this focus is activated, remains accessible over a certain period of time, and can be easily retrieved if re-entered into the focus of attention. Both of these working memory models include memory and executive and attentional processes. Consequently, working memory can be understood as the interface between these cognitive domains. It possesses high practical relevance by providing the basis for numerous higher-level cognitive operations in everyday-life such as orientation and navigation. For efficient orientation and navigation, spatial information has to be encoded, maintained, updated, and retrieved. All of these processes are spatial working memory operations per definition. Consequently, an agerelated dysfunction of one these sub-processes may explain the difficulties of older adults in orienting and navigating in unfamiliar environments $[19,20]$.

Taken together, healthy seniors (approximately over the age of around 60) show cognitive alterations in various neuropsychological domains with the most robust changes being reported for working memory, executive functioning, and processing speed.

Most of the cross-sectional results on age-related cognitive alterations suggest a relatively linear decline of these domains across the lifespan starting at an age of 20, which is at least partly confirmed by longitudinal data $[1,7,13,21]$. Noteworthy, other longitudinal studies suggest a curvilinear course with a sharper decline at older ages [3, 7]. All in all, there seem to be marked differences regarding the onset and progress of age-related cognitive changes [13], which again is associated with the efficiency of compensational mechanisms [5]. Despite compensation, though, every aging process goes along with reduced cognitive performance sooner or later. Reasons for these changes are structural and functional cerebral alterations. While functional changes particularly comprise changes in neural activation, functional connectivity, and neurotransmission, structural changes include grey and white matter deterioration.

\section{Age-related changes in grey matter}

Age-related grey matter changes can be reflected by cortical thinning, a decreased brain tissue surface, or a progressive reduction of brain volume after the second decade of life [22-24]. Reasons for this decline are a shrinkage of neurons, a reduction of synaptic spines, and a reduced number of synapses rather than neuronal loss [6]. Global grey matter volume loss seems to show a relatively constant progression until the age of 70 [23] with an annual atrophy rate of approximately $0.2 \%$ [25]. Afterwards, however, longitudinal data suggest an accelerated degeneration (0.3-0.5\%) [25], particularly of the hippocampus [26, 27]. Noteworthy, more recent longitudinal studies reported decelerated changes in the prefrontal cortex and other brain regions as well, indicating that the pattern and rates of grey matter atrophy in older adults are highly region-dependent [24].

Moreover, grey matter volume reductions do not equally involve all brain regions. Whereas reductions are consistently reported for superior parietal and inferior temporal brain regions as well as for hippocampus, insula, caudate, putamen, and particularly prefrontal cortex [6, 26, 28-32], other brain regions as parahippocampal gyrus, cingulate cortex, or occipital brain regions appear to be relatively spared from age-related change [30]. In fact, there is evidence for a specific vulnerability of frontostriatal brain regions: Bauer and colleagues, for example, used voxel-based morphometry to identify pronounced age-related grey matter volume reductions in the insula, the nucleus caudatus, and the prefrontal cortex, whereas grey matter atrophy was not evident in other brain regions [4].

To be able to draw conclusions on the meaning of these grey matter changes for cognition, most brain imaging studies related regional brain volume to cognitive performance in specific cognitive subdomains. Longitudinal data revealed an association between frontal brain volume in seniors and decreased executive task performance 12 months later [33]. Other studies also consistently reported correlations between frontal brain volume and memory, attention, and executive task performance [4, $11,34,35]$. These results highlight the relevance of prefrontal brain structures for different cognitive processes, which is confirmed by functional imaging data [36]. Since working memory can be comprehended as an interface between memory, attention, and executive processes, it is not surprising that numerous studies found relations between frontal 
brain volume and working memory performance as well (e.g., [34, 37]). Finally, striatal and hippocampal grey matter volume appear to be important predictors for memory performance in older adults, although an association between hippocampal volume and memory was not observed in all studies [4, 34]. Moreover, many of the findings do not necessarily imply that hippocampal grey matter volume reduces with age, because the same relationship may be found in younger individuals. In fact, findings on age-related hippocampal shrinkage are partly heterogeneous as well: Although many studies revealed a negative relationship between hippocampal grey matter volume and age (e.g., [26, 27, 30, 38]), others did not [28].

Taken together, decreased cognitive performances in (working) memory, attention, and executive functions can at least partly be attributed to age-related grey matter atrophy of prefrontal brain regions.

\section{Age-related changes in white matter}

Age-related white matter changes are particularly characterized by the deterioration of fiber connections caused by the loss of myelin. As a consequence, the length of myelinated axons and white matter volume are reduced in older adults [6]. Contrary to grey matter volume loss, however, white matter volume reduction shows a different pattern. The results of Good and colleagues, for example, did not reveal a reduction of global white matter volume across the lifespan at all [23]. However, results suggested an inverted U-shaped pattern in female subjects which was confirmed by more recent research. Westlye and colleagues examined 430 individuals between 8 and 85 years of age and showed that global white matter volume increased until an age 50 years to decrease afterwards [39-41]. This inverted U-shaped pattern of white matter volume loss was observed for multiple brain regions.

Noteworthy, the development of neuroimaging techniques in the last decade has yielded advanced methods to examine white matter changes in older individuals. Diffusion tensor imaging (DTI), for example, provides the opportunity to examine microstructural white matter alterations with advancing age. DTI provides different measures for the structural integrity of fiber systems, the most prominent of which are fractional anisotropy (FA) and mean diffusivity (MD). FA and MD indicate the integrity of axons and cellular membranes. Thereby, higher FA values and lower MD values reflect a higher degree of structural integrity. Similar to age-related white volume loss, changes in FA seem to follow an inverted U-shaped pattern with a maximum at an age of thirty years followed by a continuous but slight decrease until an age of 65 years and an accelerating decrease afterwards [41, 42]. Changes in MD show an analog pattern (U-shaped) providing further evidence for a three-stage model of white matter alterations across the lifespan with accelerated changes in early and late life decades. Similar to some results on white matter volume, regional differences seem to be rather discreet. In fact, changes of white matter integrity were not only observed in frontal white matter but also in other brain regions [41], indicating that agerelated alterations in FA and MD follow a similar course in all brain regions. Thereby, most findings revealed stronger associations between FA and cognitive performance than between MD and cognitive performance, indicating that age-related FA reductions seem to be more relevant for cognitive changes than increases in MD [43].

However, similar to the accentuated frontal grey matter atrophy across the lifespan, other studies point toward a specific vulnerability of frontal fiber connections [5, 23, 44, 45]. In fact, many studies reported an anterior-posterior gradient of FA reductions in older individuals indicating a specific vulnerability of prefrontal connections with advancing age [9, 46-50]. O'Sullivan and colleagues, for example, reported that frontal FA in older individuals was reduced by $10 \%$, whereas FA in middle and posterior brain regions was reduced by $6 \%$ or unchanged, respectively. A similar anterior-posterior gradient was reported for the increase in MD $[9,46]$. However, the anteriorposterior gradient of white matter degeneration does not seem to be universally valid [51] but may particularly apply to specific fiber systems such as afferent and efferent prefrontal connections [52]. Salat concluded that small and less myelinated fibers are particularly vulnerable to age-related decline, such as fiber tracts whose myelinization is completed in later life. Results like these support the validity of the "last in, first out" hypothesis suggesting an earlier degeneration of later developed brain regions $[49,52]$.

To examine the impact of these age-related white matter changes on cognitive performance, regional white matter volume and integrity were correlated with performance in different cognitive domains. Most studies reported positive relations of frontal white matter volume and integrity with processing speed, executive functioning, and working memory $[8-10,44]$. Noteworthy, most of these cognitive 

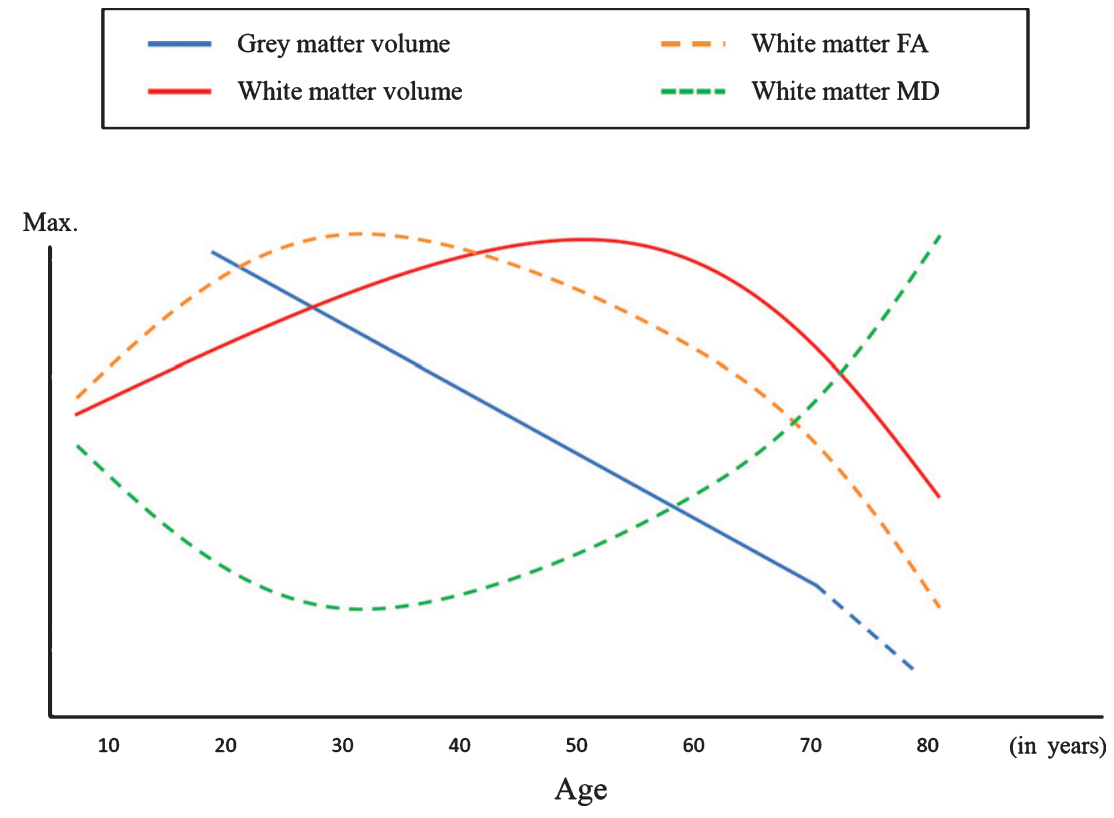

Fig. 1. Hypothetical model of global structural cerebral changes across the lifespan (particularly based upon the results of Good et al. [23] and Westlye et al. [41]). The diagram illustrates the different patterns of changes in grey matter volume, white matter volume, and white matter integrity (FA, fractional anisotropy; MD, mean diffusivity). Relations between the different measures are not considered. Whereas global grey matter volume alterations describe a relatively linear decline until an age of 70 (analog courses for cortical thinning and brain tissue surface), white matter volume and integrity show inverted U-shaped patterns with peaks in different decades of life. The blue dashed line indicates that there may be accelerated grey matter atrophy at older ages (with region-specific differences) [24, 25].

processes do not only rely on the integrity of frontal white matter but also on connections between frontal and other task-related brain regions. Sasson and colleagues, for example, reported an association between the integrity of anterior-posterior connections and executive functioning [53]. Taken together, there is much empirical evidence for increasingly defective anterior and posterior fiber tracks with advancing age. These deficiencies lead to a cortical disconnection impeding the communication between the prefrontal cortex and other brain regions and leading to decreased cognitive performance particularly in executive tasks $[54,55]$.

\section{Conclusions on age-related changes in brain structure}

In conclusion, results point toward different structural cerebral changes with advancing age. These changes affect different brain regions and their fiber connections and may explain 25-100\% of performance differences between older and younger individuals in specific cognitive domains [6]. Grey matter volume reaches its maximum in early adulthood and then shows a relatively linear decline until region-specific accelerations or decelerations of cortical atrophy can be observed at older ages (Fig. 1).

By contrast white matter volume and integrity show inverted U-shaped patterns with peaks after the third and the fifth decade of life and accelerated changes in early and late life decades. The ratio between grey and white matter atrophy appears to be relatively balanced. In fact, there are studies reporting more pronounced white matter than grey matter changes in older individuals while other findings suggest the opposite pattern [44]. Interestingly, the different peaks in the course of white matter changes indicate that white matter volume and white matter integrity may be complementary measures for the status of white matter $[41,56]$, since white matter integrity already declines when white matter volume reaches its maximum.

The described patterns of structural decline can manifest in various brain regions, although prefrontal structures show a specific vulnerability to age-related degeneration. This frontal vulnerability applies to both grey and white matter degeneration and leads to cognitive decline in different cognitive domains such as executive functioning, attention, memory, and working memory. 
Age-related changes in cerebral activation

Other important reasons for age-related changes in cognition are functional cerebral changes with advancing age. Contrary to structural imaging approaches, neurophysiological methods as electroencephalography (EEG) or magnetoencephalography (MEG) as well as functional imaging techniques as functional magnetic resonance imaging (fMRI) provide the opportunity to examine neural activation during the performance of a specific cognitive task. Thereby, EEG and MEG (for reviews, see $[57,58])$ provide a high temporal resolution that enables direct recording of neural activity, whereas fMRI has a high spatial resolution allowing a quite accurate localization of activation (albeit slightly delayed). Hence, specific cognitive sub-processes can directly be attributed to the activation of specific brain regions. Noteworthy, there is a great overlap between the neural networks associated with cognitive domains as memory, attention, or executive functioning. Episodic and semantic memory processes (e.g., encoding, consolidation, retrieval) were particularly attributed to activation in left prefrontal cortex and mediotemporal brain regions (i.e., hippocampus, entorhinal cortex), while attentional processes (e.g., focused attention, processing speed) and executive functions (e.g., cognitive control) were linked to prefrontal, parietal, and striatal regions [59-61]. All of these cognitive domains are associated with prefrontal cortex activation and the same applies to working memory operations. Working memory probably is one of the best explored functions in healthy aging and many of the findings on its mechanisms seem to be applicable to other cognitive domains as well. Working memory is associated with neural activation of an anterior-posterior network particularly including prefrontal and posterior parietal cortices [36, 62]. Advancing age is associated with activation changes within this network, whereby prefrontal brain regions, equivalent to agerelated changes in brain structure, seem to show a specific functional vulnerability. In fact, numerous studies reported prefrontal activation differences between younger and older individuals [63,64]. The kind of these differences, however, varies across studies and can manifest in quantitative or qualitative differences. Quantitative differences include either increased ('hyperactivation') or decreased ('hypoactivation') frontal brain activation in older compared to younger individuals, whereas qualitative activation differences imply the recruitment of additional brain structures or increased bilaterality in older adults. In addition to the heterogeneity of these differences, their interpretation is subject to a high degree of variability. Frontal hypoactivation, for example, was interpreted as high neural efficiency or a reduction of neural resources (neural dysfunction), whereas frontal hyperactivation or increased bilaterality were attributed to neural inefficiency, neural compensation or reduced regional specificity [63, 65-79]. Reasons for these apparently inconsistent interpretations may be found in differing study designs (different paradigms, methods, etc.). Moreover, the kind of activation differences between older and younger individuals is not only dependent from age but also from numerous other factors.

Performance accuracy and task load. Obviously, age-related activation differences cannot be interpreted without considering the impact of performance accuracy which is why brain data results were controlled for accuracy effects in some studies (e.g., by excluding incorrect trials). In fact, prefrontal hyperactivation or increased bilaterality associated with increased or equivalent performance accuracy clearly point toward a compensatory recruitment of neural resources. In this case, an older individual enables more neural resources to achieve the same performance as a younger individual. By contrast, prefrontal hyperactivation or increased bilaterality associated with lower performance accuracy are rather signs of neural inefficiency or reduced regional specificity. Moreover, hypoactivation together with low performance accuracy points toward limited neural resources, whereas hypoactivation in the presence of high performance accuracy suggests a high degree of neural efficiency.

Another factor modulating age-related activation differences is the load level of the applied task. In fact, pronounced age effects can be identified by paradigms in which task demands are experimentally manipulated. On the behavioral level, an increase of task demands requires the recruitment of additional resources which are often limited in older individuals. On the neural level, these restraints are reflected by activation differences between older and younger individuals particularly within prefrontal cortex, as revealed by both imaging and neurophysiological data [79-84].

CRUNCH. The most popular aging model considering both performance accuracy and task load is the Compensation-Related Utilization of Neural Circuits Hypothesis (CRUNCH) invented by Reuter-Lorenz 


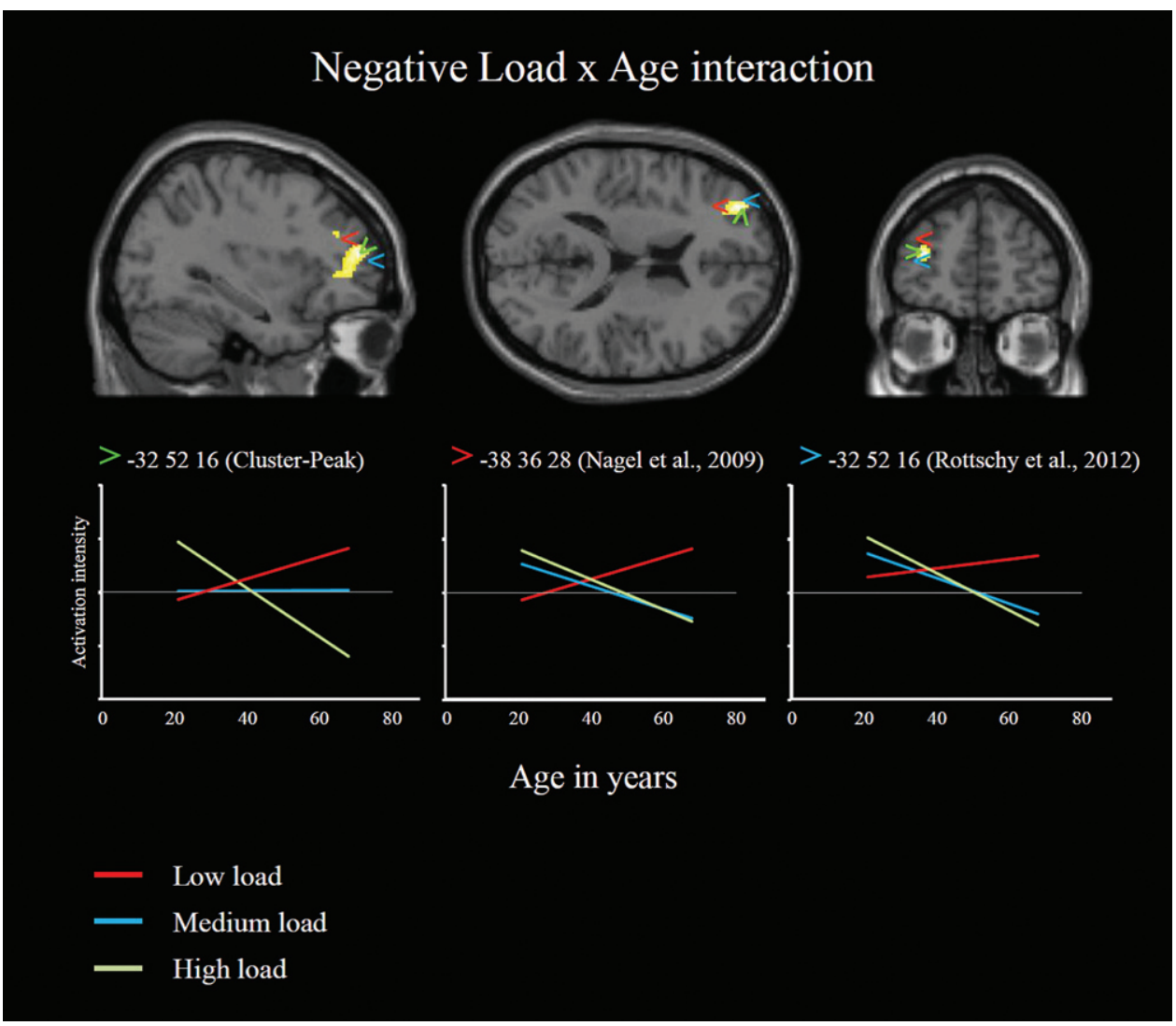

Fig. 2. The CRUNCH effect. Whole-brain cluster-level analysis with a threshold of $Z>3.1$ and a cluster significance threshold of $\mathrm{p}_{\mathrm{FWE}}<0.05$ revealed a negative load $\times$ age interaction within a large cluster located in anterior dorsolateral prefrontal cortex (unpublished material from Toepper et al. [85]). The diagrams illustrate activation intensity at low, medium, and high task load dependent from age within the peak of this cluster and two study-independent peaks identified by conjunction analyses across different age groups and load levels [69] and across 124 verbal and nonverbal working memory tasks [62]. Results showed analogue activation patterns for all three peaks indicating increasing activation intensity with advancing age at low load and decreasing activation intensity with advancing age at high load as well as higher activation intensity in older compared to younger individuals at low load and lower activation intensity in older compared to younger individuals at high load (double dissociation).

and Cappel [79]. The CRUNCH model postulates that older individuals show unimpaired working memory performances at low task demands but frontal hyperactivation or increased bilaterality reflecting a recruitment of additional neural resources to compensate for an age-related reduction of working memory capacity. At high task demands, by contrast, older individuals show poorer performances than younger individuals as well as frontal hypoactivation indicating a limitation of neural resources. The CRUNCH assumptions could be replicated in numerous studies [69, 80-83], so that there is growing evidence for a double dissociation of load-related activation between older and younger adults. Toepper and colleagues, for example, used fMRI to examine spatial working memory related brain activation in 45 healthy volunteers between 20 and 68 years of age [85]. Working memory load was manipulated by the number of displayed target stimuli. Older subjects showed higher prefrontal activation at low task load than at high task load, whereas younger participants showed the opposite pattern. Moreover, older participants showed more activation than younger participants at low task load and less activation than younger participants at high task load (Fig. 2).

The results confirm the CRUNCH assumptions indicating that the recruitment of neural resources is impaired with advancing age. Moreover, the results argue for a linearly increasing neural dysfunction with an onset in early adulthood. Contrary to the CRUNCH assumptions, however, the findings indicate that prefrontal hyperactivation at low task load may also reflect neural inefficiency rather than compensation. 
High-versus low-performers. Another option to examine the impact of behavioral performance on brain activation is the comparison between high- and low-performing individuals in different age cohorts. An fMRI study of Bauer and colleagues, for example, revealed that older high-performers similar as younger high-performers showed increasing prefrontal activation with increasing working memory load [86]. This 'youth-like' pattern was less differentiated in older individuals but pointed toward an efficient recruitment of neural resources at increasing task demands. Younger low-performers also showed increased activation at medium task load, but no further increase at high task load. Consequently, neural resources of younger low-performers appeared to be exhausted earlier compared to younger and older high-performing subjects. The poorest performances were shown by older low-performers. In addition, older low-performers did not show an increased neural response to increasing task load suggesting that older low-performing subjects already reached their resource ceiling at low task demands (Fig. 3).

Very similar effects of performance level on the recruitment of neural resources were previously reported by Nagel and colleagues [69], although a different paradigm, different methods, and different load levels were utilized (e.g., parallel versus serial target presentation, load levels 1-3-7 versus 4-5-6). Contrary to the results of Bauer and colleagues, however, Nagel and colleagues reported a quadratic trend in older low-performers within right dorsolateral prefrontal cortex suggesting that older low-performers show increased activation at low load levels before activation intensity reaches a plateau and decreases at high task load. Despite this difference, the two studies provide a good example for the validity and replicability of complex aging effects [87], particularly in the context of the ongoing discussion about the limited reproducibility of psychological studies [88].

\section{Age-related changes in functional connectivity}

Besides age-related changes in neural activation, functional cerebral changes are characterized by changes in functional connectivity. Functional connectivity describes the degree of how much activation in one brain region is correlated with activation in another brain region and therefore provides a measure of intracerebral communication. Particularly, frontal functional connections are associated with performance accuracy [70,89] and appear to be defective in older adults. This frontal connectivity dysfunc-

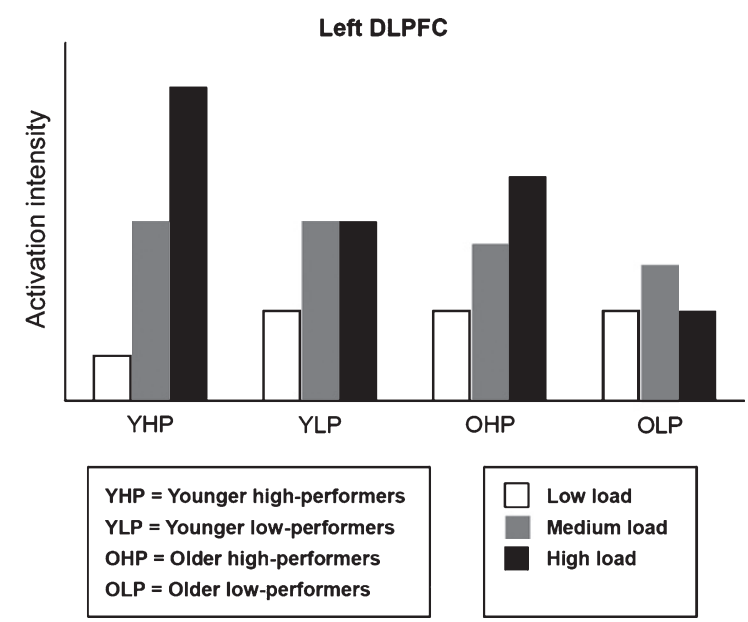

Fig. 3. Hypothetical model of left dorsolateral prefrontal cortex (DLPFC) activation modulated by age and performance level (particularly based upon the results of Nagel et al. [69] and Bauer et al. [86]). The bar chart indicates a flexible upregulation of DLPFC activation in YHP as neural response to increasing load. OHP show a similar though less differentiated pattern indicating a flexible recruitment of neural resources similar to that of YHP. By contrast, neural resources appear to be exhausted at medium or low load in YLP, and OLP respectively. Please notice that qualitative group differences are shown; exact quantitative relations were not considered.

tion implies impaired bifrontal, frontoparietal, and frontostriatal connections [90-92]. Toepper and colleagues, for example, used fMRI during a spatial working memory task and found a more diffuse connectivity pattern in older compared to younger adults [93] indicating less specific representations and neural circuits $[94,95]$. Moreover, older adults showed reduced functional connectivity between dorsolateral prefrontal and orbitofrontal cortices associated with a disproportional accuracy decline on the behavioral level. These findings suggest that the functional integrity of frontal neural circuits is reduced in older adults leading to less flexible and efficient working memory control processes [95-97]. These assumptions are in line with other studies attributing decreased functional connectivity to the degeneration of so-called 'hubs' [98]. Hubs facilitate the communication within and between different network modules and enable a flexible and efficient intracerebral communication. In healthy seniors, one of these hubs is located in orbitofrontal cortex [98]. Age-related orbitofrontal atrophy $[4,30]$ may damage those hubs and, as a consequence, lead to frontal connectivity dysfunctions and impaired cognitive performance.

Noteworthy, frontal connectivity changes may not only manifest in decreased but also in increased functional connectivity. For example, some studies point 
toward increased frontal connectivity as sign of neural compensation [99] or dedifferentiation [57]. Such results suggest that factors as performance accuracy or task load do not only modulate age-related changes in neural activation but also in functional connectivity. In fact, higher functional connectivity between different prefrontal brain regions and between prefrontal and parietal brain regions does not only seem to be associated with higher performance accuracy but also with increasing task demands [70, 89, $100,101]$. Younger individuals and high-performing seniors, for example, showed increased functional connectivity as neural response to increased task load, whereas low-performing seniors did not [70]. Consequently, age-related changes in functional connectivity seem to follow a similar pattern as changes in activation [70, 102]. Moreover, the functional connectivity results argue for a specific vulnerability of the prefrontal cortex and particularly highlight the relevance of rostral and dorsolateral prefrontal regions for age-related cognitive decline.

\section{Age-related changes in neurotransmission}

Noteworthy, age-related functional cerebral changes also include changes in neurotransmission. Among these changes, the reduction of dopamine seems to be the most relevant factor for reduced cognitive performance [103-105]. In particular, there is strong evidence for an age-related dysfunction of the nigrostriatal dopamine system as reflected by the reduction of pre- and postsynaptic receptor densities (i.e., $\mathrm{D}_{1}$ and $\mathrm{D}_{2}$ receptors), for example [103]. With advancing age, impaired dopaminergic modulation leads to impaired cognitive performance in multiple domains, particularly including processing speed, episodic memory, cognitive control, and working memory [104]. Thereby, most studies reported a linear decrease of dopamine with advancing age, although there is also evidence for an accelerated decline in later decades of life [103]. In general, the relation between dopamine and cognition describes an inverted U-shaped pattern with low and high levels of dopamine being associated with poor cognitive performance [104]. In fact, the best dopamine level seems to be reached in early adulthood, whereas too low levels in old age or too high levels in adolescence may result in cognitive dysfunctions. One possible reason for reduced dopamine in older adults certainly is the loss of dopamine cell bodies in the substantia nigra across the lifespan [103]. Future research must show how the correlative triad between dopamine, cognition, and age is related to other factors such as structural integrity or functional connectivity, for example.

\section{Conclusions on age-related changes in brain function}

Age-related changes in brain function include activation changes in rostral parts of the dorsolateral prefrontal cortex, reduced functional connections to other frontal, parietal, and striatal brain regions as well as impaired dopaminergic transmission. Importantly, changes in activation and functional connectivity are modulated by different factors such as performance accuracy or task load. However, future research studies should consider the impact of other factors as well. One of these factors is the specific localization of age-related activation changes. In fact, the prefrontal cortex can be divided into different hierarchically organized functional modules that may be differentially affected by advancing age. The most prominent theories on this topic either propose a dorsolateral-ventrolateral [106-111] or a rostral-caudal $[112,113]$ prefrontal cortex organization with dorsolateral or rostral parts being associated with higher-level executive processes, whereas ventrolateral or caudal parts are rather related to the relatively passive maintenance of information $[114,115]$. Thereby, increasing age seems to affect activation particularly within dorsolateral prefrontal cortex or rostral prefrontal cortex, respectively $[85,86,116,117]$.

\section{General conclusions on age-related changes in brain structure and brain function}

In conclusion, healthy aging goes along with structural and functional cerebral changes. Structural changes comprise both grey and white matter atrophy, while functional changes include changes in activation, functional connectivity, and neurotransmission. All of these changes are associated with decreased cognitive performance in older adults. Moreover, numerous studies point toward a specific vulnerability of the prefrontal cortex with advancing age.

Future research should focus on the specific relations between structural and functional alterations. Reuter-Lorenz and Cappell, for example, argued that regional hyperactivation in older individuals may only indicate compensatory processes, if this hyperactivation was associated with increased cognitive performance and likewise with structural decline 
[79]. Otherwise, it would remain unclear what older individuals must actually compensate for. In this context, some studies showed that the structural integrity of frontal fiber connections was associated with activation intensity in prefrontal brain regions as well as with cognitive performance accuracy $[10,118]$. In fact, only the methodical combination of MRI-, DTI-, and behavioral measures may allow valid conclusions on the specific mechanisms underlying age-related cognitive deterioration [43, 78].

\section{NEUROCOGNITIVE CHANGES ASSOCIATED WITH ALZHEIMER'S DISEASE}

Age-related changes in brain structure and function go along with impaired cognitive performance. Particularly, reduced processing speed may impede certain activities in everyday life. However, these cognitive changes do not severely affect basic routines (e.g., body care). By contrast, neurodegenerative disorders are characterized by severe cognitive deficits eventually leading to a complete loss of autonomy. The most common neurodegenerative disorder is Alzheimer's disease (AD). AD is characterized by pathological cerebral changes that already manifest in the fifth decade of life long before first cognitive changes become apparent or structural atrophy can be objectified by MRI techniques [119, 120]. Consequently, $\mathrm{AD}$ takes a long subclinical course and may therefore not necessarily be regarded as a typical geriatric disease. Nevertheless, age is the main risk factor for $\mathrm{AD}$ which leads to exponentially increasing incidence and prevalence rates across the lifespan. The course of AD can be subdivided into different stages with a total duration between five to eight years $[121,122]$.

Main characteristics of $\mathrm{AD}$ are the formation of extracellular plaques and intracellular neurofibrillary tangles, mainly consisting of amyloid- $\beta$ peptides and hyperphosphorylated tau protein, respectively. Across the different disease stages, the formation of plaques and tangles follow specific patterns [123, 124]: Plaques first manifest in the temporal lobe and the orbitofrontal cortex to expand to different cortical association cortices as well as to hippocampus, amygdala, diencephalon, and basal ganglia. In later disease stages, mesencephalon, brain stem, and cerebellum are affected. Neurofibrillary tangles manifest in the locus coeruleus as well as in entorhinal and transentorhinal cortices. Afterwards, hippocampus and frontal brain regions are affected, before neurofibrillary changes involve all cortical areas in later disease stages. The formation of plaques and tangles is caused by different biochemical processes. Eventually, this cascade leads to cerebral tissue damage, synaptic failure, and cell death [125-127]. Noteworthy, $\mathrm{AD}$ can be rather regarded as a synaptic dysfunction than as a neural dysfunction since the loss of synapses seems to exceed the loss of neurons and represents the strongest correlate of dementia $[127,128]$.

Noteworthy, the extent of the described pathologies (plaques and tangles) can be quantified by an analysis of cerebrospinal fluid (CSF). Plaques consist of accumulated amyloid- $\beta$ (A $\beta)$ peptides whose main component is $A \beta$ 1-42 (A $\left.\beta_{42}\right)$. As a result, reduced $A \beta_{42}$ concentrations can be observed in the CSF of AD patients [129-131]. Neurofibrillary tangles, by contrast, mainly consist of hyperphosphorylated tau ( $\mathrm{p}$-tau) protein, additionally leading to an increased p-tau concentration [132, 133]. Finally, as a consequence of the neuronal injury caused by these events, the total-tau (t-tau) protein concentration in the CSF of AD patients is increased as well $[119,120,132,134]$. Hence, AD patients consistently show patterns of decreased $A \beta_{42}$ and increased ptau and t-tau concentrations [135-137]. All of these markers provide high diagnostic accuracy rates with sensitivity and specificity scores between $80 \%$ and 90\% [135]. Different combinations of these markers as the ratios between $A \beta_{42}$ and t-tau or between $A \beta_{42}$ and $A \beta_{40}$ peptides can even slightly increase diagnostic accuracy. Particularly $A \beta_{42}$ and t-tau are associated with the cognitive key symptoms of AD [138] and can predict conversion to AD dementia in patients with mild cognitive impairment (MCI) $[139,140]$.

\section{$A D$-related changes in cognition}

As mentioned above, the main consequence of these AD-related pathological changes are cognitive deficits. During the progression of the disease, these deficits lead to restricted daily routines [141]. Both cognitive deficits and restricted daily routines belong to the main criteria of $\mathrm{AD}$ diagnosis. The first $\mathrm{AD}$-related cognitive symptoms are episodic memory deficits $[142,143]$ particularly involving the learning of new information. As a consequence, $\mathrm{AD}$ patients typically show poor retrieval and recognition performances at learning tasks [5, 144-148]. The main reason for these deficits is an encoding 
dysfunction that impedes the consolidation of new information into long-term memory and with that the formation of cerebral representations. As a consequence, $\mathrm{AD}$ patients are not able to recall learning content. Moreover, they do not profit from cues typically indicated by a high number of false-positive responses during item recognition. Impaired retrieval and recognition performances are the first signs of an AD-related episodic memory dysfunction and can therefore be regarded as the cardinal symptoms of AD-related cognitive decline.

Besides episodic memory, semantic memory is affected in early $\mathrm{AD}$ stages often being reflected by word-finding difficulties $[149,150]$. Due to the degeneration of semantic networks, $\mathrm{AD}$ patients have restricted access to semantic memory content [151-153]. As a consequence, they typically show poor performances in naming tasks that require the identification of objects. Toepper and colleagues [154], for example, qualitatively analyzed the answers of $40 \mathrm{AD}$ patients and 40 healthy controls in the Boston Naming Test [155]. Besides pronounced naming deficits in $\mathrm{AD}$ patients, results showed that the semantic proximity of the answers to a displayed object was associated with semantic network integrity and global cognitive functioning. Moreover, there was evidence for a top-down deterioration of semantic network integrity in $\mathrm{AD}$, beginning with higher-order categories.

Other cognitive domains being affected by $\mathrm{AD}$ are orientation $[19,156]$ and executive functioning [157-161], the latter of which may involve specific sub-processes as abstract thinking, cognitive flexibility, and inhibition [162-165]. Regarding inhibitory deficits, particularly the active or intentional inhibition of irrelevant information appears to be impaired in $\mathrm{AD}[164,165]$. Further progression of the disease then leads to impaired attention, albeit attentional processes as processing speed appear to be longer preserved from AD-related change than other cognitive domains [121, 166].

Importantly, all of the cognitive deficits described above also affect higher-level operations. Common examples are symbol comprehension [167] or driving skills [168], both of which contribute to autonomy in everyday life.

Late AD stages are then associated with aphasia, apraxia, behavioral disorders, affective symptoms, and motor dysfunctions. Due to immunodeficiency and dysphagia, $\mathrm{AD}$ patients are at some point particularly vulnerable to respiratory infections representing the most frequent cause of death.
The progression of AD-related cognitive deterioration appears to be slower in early and late disease stages than in middle stages [169], although there is also evidence for linear decline [170]. Disease progression is characterized by high betweensubject variability. Moreover, so-called 'plateaus' are reached during which cognitive performance remains relatively stable [171]. Number and duration of those plateaus are also subject to high variance. The typical deficit profile in $\mathrm{AD}$, however, is characterized by pronounced memory deficits (episodic and semantic) representing the cognitive key symptom of the disease. In addition, early executive and orientation deficits can be observed, whereas processing speed is relatively preserved until further progression of the disease. Reasons for these deficits are structural and functional cerebral changes including grey and white matter degeneration as well as changes in neural activation, functional connectivity and neurotransmission.

\section{$A D$-related changes in grey matter}

The loss of synapses and neurons in $\mathrm{AD}$ results in reduced global grey matter volume with annual atrophy rates between $2-3 \%$ and an accelerated decline with disease progression [25]. The volume loss follows a similar pattern as the expansion of amyloid plaques and neurofibrillary tangles as described above [172]. Volume loss initially affects hippocampus and entorhinal cortex [43, 173]. In fact, there is metaanalytical evidence that patients in the prodromal stage of $\mathrm{AD}$ exclusively show grey matter volume reductions in these brain regions [172, 174]. Hippocampal volume loss is associated with episodic memory deficits representing the cognitive cardinal symptom of $\mathrm{AD}$ [175]. In early $\mathrm{AD}$ stages, it is reduced by $10 \%$ up to $30 \%$ in later disease stages. The annual reduction rate is about $4-8 \%$ in $\mathrm{AD}$ patients compared to less than $2 \%$ in healthy seniors [25, 43]. For AD-related entorhinal atrophy, even higher annual reduction rates are reported.

Following these mediotemporal volume reductions, grey matter atrophy affects different association cortices [43, 176, 177]. Thereby, structural volume reductions spread from middle and inferior temporal gyri, inferior parietal lobe, and posterior cingulate cortex to other parts of the parietal lobe, frontal brain regions, and finally to anterior parts of the cingulate cortex [178]. Noteworthy, posterior parietal and posterior cingulate atrophy seem to be associated with 
an earlier onset and a faster progression of the disease [179]. By contrast, occipital brain regions as well as primary sensory and motor regions seem to be relatively preserved from $\mathrm{AD}$-related grey matter atrophy.

Contrary to healthy seniors who show a specific vulnerability of the prefrontal cortex and a relatively preserved integrity of the hippocampal formation, AD patients show the opposite pattern $[180,181]$. In fact, Head and colleagues suggested a frontohippocampal dissociation between healthy aging and $\mathrm{AD}$, which was supported by the results of Jack and colleagues who also reported rather discrete frontal atrophy in AD patients, whereas pronounced volume reductions were found in mediotemporal brain regions and the parietotemporal junction.

\section{$A D$-related changes in white matter}

Although $\mathrm{AD}$ is mainly characterized by grey matter atrophy, white matter is also affected. Similar to grey matter volume reductions, white matter volume loss particularly involves mediotemporal structures as hippocampus and entorhinal cortex [182]. Moreover, white matter atrophy in inferior parietal, temporal, and anterior frontal brain regions as well as in posterior cingulate cortex, posterior corpus callosum, and cerebellum are reported [176, 183]. Some of these changes already manifest in prodromal stages of the disease [177].

Moreover, AD-related white matter changes are characterized by reduced structural integrity (decreased FA and increased MD). These changes particularly include intracortical projections in temporal, parietal and frontal brain regions, whereas extracortical fiber systems as sensory or motor projections are relatively preserved [43, 184, 185]. Again, these changes particularly affect hippocampal, parahippocampal, and entorhinal connections [186-188] but also posterior cingulate cortex, posterior corpus callosum [182, 189], anterior temporal lobe [190], and fasciculus longitudinalis superior [191]. Consistent with the results on AD-related grey matter changes, DTI results do not suggest a specific vulnerability of frontal brain regions. Instead, there is evidence for a posterior-anterior gradient of structural degeneration with a specific vulnerability of posterior structures and a relative preservation of the frontal brain [188, 192]. This gradient was observed for reduced FA as well as for increased MD.

Moreover, there is evidence for an association between white matter integrity and cognition [193].
In fact, global and frontal white matter integrity as well as integrity of fornix, cingulum, cingulate cortex, and corpus callosum were shown to be correlated with global cognitive performance. In addition, there is evidence for a relationship between regional white matter integrity and specific cognitive subfunctions. Episodic memory deficits, for example, are particularly associated with structural integrity of cingulum, fornix, and fasciculus uncinatus. Moreover, associations between memory retrieval deficits and reduced structural integrity in temporal and posterior cingulate cortices, between executive dysfunctions and reduced frontal integrity and between impaired nonverbal memory or verbal fluency and integrity of the corpus callosum were reported [175, 193, 194]. Altogether, the degeneration of fiber connections between mediotemporal structures and corpus callosum or frontal brain regions seem to be of particular relevance for AD-related cognitive decline [194, 195]. Thereby, contrary to healthy seniors, more robust correlations between $\mathrm{MD}$ and cognitive performance than between FA and cognitive performance were observed in $\mathrm{AD}$ patients, indicating that the increase of MD seems to be more important for ADrelated cognitive decline than the decrease in FA $[43,175,184]$.

\section{Conclusions on $A D$-related changes in brain structure}

In conclusion, the results on $\mathrm{AD}$-related changes in brain structure point toward a posterior-anterior gradient of grey and white matter degeneration including a specific vulnerability of the medial temporal lobe and posterior parts of the corpus callosum. Fiber tracts connecting mediotemporal brain structures with the corpus callosum and the frontal lobe appear to be particularly vulnerable and their degeneration leads to increasing cognitive deficits during the progression of the disease. Future research should specify the association between grey and white matter atrophy. Grey matter volume loss and reductions of white matter integrity, for example, seem to show similar patterns [175]. Moreover, Villain and colleagues [196] showed that hippocampal grey matter volume loss was associated with reduced white matter integrity of the cingulum which again was correlated with hypometabolism in the right temporoparietal association cortex and different structures of the Papez circuit (posterior cingulate cortex, thalamus, mamillary bodies, hippocampus, parahippocampal gyrus). Moreover, there is evidence for an asso- 
ciation between hippocampal grey matter volume and FA values of the fasciculus uncinatus which again are associated with episodic memory deficits [194]. These results suggest that an AD-related hippocampal disconnection is linked to hippocampal atrophy and contributes to early episodic memory deficits. In fact, only the methodological combination of different measures may allow more specific conclusions on the mechanisms leading to cognitive decline in AD.

\section{$A D$-related changes in cerebral activation}

Next to structural cerebral changes, AD is characterized by functional changes. Neurophysiological studies consistently revealed altered neural activity in patients with $\mathrm{AD}$ or MCI, being associated with dysfunctions in various cognitive domains such as memory, attention, working memory or spatial abilities [57, 197-200]. Since memory processes are initially affected by $\mathrm{AD}$, first activation changes can be observed during memory tasks. Sperling, for example, found reduced mediotemporal activation (i.e., hippocampal formation) during the encoding of new information [201]. By contrast, increased mediotemporal activation was reported for memory retrieval possibly reflecting successful compensation [184], which is consistent with the assumption that mediotemporal hyperactivation can particularly be observed in early AD stages. Modulated by performance accuracy, however, this hyperactivation may reflect both successful [202] or inefficient compensatory mechanisms [203]. The latter finding goes better with studies reporting an association between early mediotemporal hyperactivation and faster cognitive decline [202].

Further progression of the disease then results in increasingly reduced mediotemporal activation and aggravating memory deficits [204]. Noteworthy, memory deficits seem to be associated with activation changes in other cortical areas as well. In fact, there is evidence for AD-related dysfunctional hypoactivation in prefrontal and parietal cortices as well as for compensatory hyperactivation in prefrontal cortex [43, 205, 206].

Besides memory deficits, there is evidence for early working memory and executive dysfunctions associated with activation changes particularly in prefrontal brain regions. Similar to the results on memory processes, compensatory prefrontal hyperactivation [207-209] as well as dysfunctional prefrontal hypoactivation $[210,211]$ were reported.
As mentioned earlier, the kind of activation changes is modulated by performance accuracy and task load. Rosano and colleagues, for example, showed that prodromal AD patients showed an upregulation of parietal brain regions as neural response to increasing task load, whereas healthy seniors showed a frontal upregulation [208]. However, the specific effects of performance accuracy and task load are less explored in AD than in healthy aging, because fMRI experiments often turn out to overextend AD patients already in prodromal stages of the disease. Consequently, fMRI studies with AD patients often utilize resting-state paradigms most of which revealed AD-related activation changes particularly in the hippocampus and the posterior cingulate cortex $[43,212]$.

\section{$A D$-related changes in functional connectivity}

With the advancement of neuroimaging techniques, $\mathrm{AD}$ is more and more regarded as a disconnection syndrome. In fact, there is growing evidence for impaired functional connectivity of neural networks in AD patients [213-215]. As in healthy seniors, a possible reason for this disconnection is the degeneration of hubs [216-218]. These hubs appear to be particularly vulnerable to AD pathology [216], which may lead to reduced functional connectivity within task-specific networks and to impaired cognitive performance [98]. For example, AD-related parietal brain atrophy (i.e., angular gyrus) impairs parietal hubs, eventually leading to a parietal disconnection [98, 217, 218]. However, frontal and hippocampal connections are also affected. Agosta and colleagues reported functional connectivity changes within frontal neural circuits associated with executive dysfunctions [219]. Other findings revealed reduced hippocampal connectivity to posterior parietal cortex, posterior cingulate cortex, and other brain regions being particularly associated with episodic memory deficits [220, 221]. Finally, functional connectivity changes can be observed in the default network as well [220, 222, 223].

Altogether, the functional connectivity results suggest a specific vulnerability of parietal and hippocampal brain regions, whereas frontal connections appear to be less affected. Dependent on moderating variables as performance accuracy or task-load, ADrelated connectivity changes may manifest in either increased or decreased connectivity reflecting either dysfunction or compensation [215, 218, 224]. 


\section{$A D$-related changes in neurotransmission}

Importantly, AD-related functional cerebral changes also include changes in neurotransmission. Among these changes, a cholinergic dysfunction represents the most relevant factor for AD-related cognitive decline. It is assumed that the degeneration of cholinergic neurons in the basal forebrain impedes synaptic processes in the hippocampus and other cortical brain regions and thus leads to memory loss including deficient encoding, consolidation, and retrieval processes [128, 225-227]. Cholinergic abnormalities can be manifold including impaired acetylcholine transport or release, for example.

Within the basal forebrain, the degeneration of neurons in the Nucleus basalis Meynert [127, 128] is of particular relevance, because this brain structure represents one of the most important nuclei in the central nervous system for the production of the neurotransmitter acetylcholine. To counteract this progressive cholinergic deficit, cholinesterase inhibitors are utilized. They enhance cholinergic neurotransmission by increasing the availability of acetylcholine in the synaptic cleft, may decelerate or even stabilize cognitive decline for one or two years but do not ensure a definite cure [228-230].

\section{Conclusions on $A D$-related changes in brain function}

In conclusion, $\mathrm{AD}$ is characterized by changes in neural activation, functional connectivity, and neurotransmission. Changes in activation and functional connectivity particularly affect mediotemporal but also parietal and frontal brain regions and may manifest in both increased and decreased activation and connectivity. Future research should focus on specific variables moderating the kind and direction of $\mathrm{AD}$ related changes, such as performance accuracy or task load. Moreover, the methodological combination of activation, functional connectivity, and neurotransmission measures should be of particular interest.

\section{General conclusions on AD-related changes in brain structure and brain function}

Taken together, AD pathology leads to grey and white matter degeneration as well as to changes in neural activation, functional connectivity, and neurotransmission. All of these changes appear to interact leading to cognitive decline. Although many of these changes also manifest in prefrontal brain regions, imaging results rather point toward a posterior-anterior gradient of functional and structural deterioration with a specific vulnerability of the medial temporal lobe.

Future research endeavors should focus on the association between functional and structural measures. Zhou and colleagues, for example, showed that reduced connectivity between hippocampus and posterior cingulate cortex is reflected by both functional and structural imaging data [221]. Other studies reported an association between hippocampal grey matter volume loss and reduced hippocampal activation [231, 232] or connectivity [194] or between specific CSF markers and white matter integrity [233, 234]. Putcha and colleagues reported a strong inverted relationship between hippocampal activation and volume in the prodromal stage of the disease (MCI) [235], while Huijbers and colleagues presented longitudinal results indicating that hippocampal volume and activation independently predicted clinical progression in patients with MCI [236]. The two latter studies suggest that activation changes are certainly associated with, but not entirely determined by structural deterioration. However, only the methodological combination of all of the described pathological markers and their relation to cognitive performance may allow more specific conclusions on the neurocognitive mechanisms underlying AD pathology.

\section{QUANTITATIVE AND QUALITATIVE DIFFERENCES BETWEEN NORMAL AGING AND ALZHEIMER'S DISEASE}

As described above, there are many similarities between normal aging and AD. Both normal aging and $\mathrm{AD}$ are associated with changes in cognition, grey and white matter volume loss, and reduced white matter integrity (changes in FA and MD) as well as changes in neural activation, functional connectivity, and neurotransmission. However, normal aging and $\mathrm{AD}$ are also characterized by numerous quantitative and qualitative differences. Quantitative differences particularly relate to the extent and progression of changes. In fact, most changes are more pronounced in $\mathrm{AD}$ and progress more rapidly providing the basis of an AD diagnosis. Noteworthy, an isolated analysis of these quantitative changes could not exclude that $\mathrm{AD}$ only reflects an accelerated aging process. However, the qualitative differences clearly argue against this view (Table 1). 
Table 1

Qualitative differences between normal aging and Alzheimer's disease

\begin{tabular}{|c|c|c|c|}
\hline & & Normal aging & Alzheimer's disease \\
\hline Cognition & & $\begin{array}{l}\text { Progressive decline } \\
\text { Accentuated executive dysfunction and } \\
\text { reduction in processing speed } \\
\text { Semantics unimpaired } \\
\text { Verbal abilities unimpaired }\end{array}$ & $\begin{array}{l}\text { Progressive decline, but plateaus } \\
\text { Accentuated memory dysfunction } \\
\text { Semantics impaired } \\
\text { Verbal abilities impaired }\end{array}$ \\
\hline Brain volume & $\begin{array}{c}\text { Grey matter } \\
\text { Grey/white matter }\end{array}$ & $\begin{array}{l}\text { Accentuated frontal atrophy } \\
\text { Anterior-posterior gradient } \\
\text { Atrophy SPL > IPL } \\
\text { Hardly atrophy of cingulate cortex } \\
\text { Atrophy of grey matter = white matter }\end{array}$ & $\begin{array}{l}\text { Accentuated hippocampal atrophy } \\
\text { Posterior-anterior gradient } \\
\text { Atrophy SPL }<\text { IPL } \\
\text { Atrophy of cingulate cortex } \\
\text { Atrophy of grey matter }>\text { white matter }\end{array}$ \\
\hline White matter integrity & & $\begin{array}{l}\text { Frontal vulnerability } \\
\text { Anterior-posterior gradient } \\
\text { Changes in FA }>\text { MD }\end{array}$ & $\begin{array}{l}\text { Hippocampal vulnerability } \\
\text { Posterior-anterior gradient } \\
\text { Changes in MD }>\text { FA }\end{array}$ \\
\hline Cerebral activation & & $\begin{array}{l}\text { Frontal changes }>\text { hippocampal changes } \\
\text { Frontal response to increasing load }\end{array}$ & $\begin{array}{l}\text { Hippocampal changes }>\text { frontal changes } \\
\text { Parietal response to increasing load }\end{array}$ \\
\hline Functional Connectivity & & Frontostriatal connections impaired & Hippocampal connections impaired \\
\hline Neurotransmission & & Accentuated dopaminergic dysfunction & Accentuated cholinergic dysfunction \\
\hline
\end{tabular}

FA, fractional anisotropy; MD, mean diffusivity; SPL, superior parietal lobe; IPL, inferior parietal lobe.

Firstly, AD-related cognitive changes seem to reach plateaus characterized by stable cognitive performance, whereas cognitive changes due to normal aging appear to show a relatively constant progression. Moreover, both AD patients and healthy seniors show memory dysfunctions, executive deficits, and cognitive slowing. However, there is evidence for an accentuated memory dysfunction in $\mathrm{AD}$, whereas normal aging is associated with accentuated executive dysfunctions and reduced processing speed. Consequently, memory deficits exceed executive deficits and cognitive slowing in $\mathrm{AD}$, whereas healthy seniors show the opposite pattern. Furthermore, semantic and verbal abilities are impaired in $\mathrm{AD}$, whereas these abilities are largely preserved in healthy aging.

In the context of structural cerebral changes, both $\mathrm{AD}$ and healthy aging are characterized by grey and white matter volume reductions. In $\mathrm{AD}$ patients, however, grey matter volume loss exceeds white matter volume loss, whereas this ratio is much more balanced in healthy seniors. Moreover, inferior parietal atrophy seems to exceed superior parietal atrophy in $\mathrm{AD}$, whereas the opposite pattern can be observed in healthy seniors. AD is associated with pronounced grey matter volume loss of the cingulate cortex, whereas cingulate cortex is relatively preserved in normal aging. AD patients show grey matter atrophy and reduced white matter integrity (reduced FA and increased MD) rather in mediotemporal (i.e., hippocampus) and parietal brain regions than in prefrontal cortex, whereas healthy seniors show a specific vulnerability of the prefrontal cortex and a relative preservation of posterior regions. Consequently, AD-related structural decline seems to follow a posterior-anterior gradient, whereas agerelated structural deterioration rather follows an anterior-posterior gradient. Moreover, increased MD seems to be a more sensitive marker of cognitive decline in $\mathrm{AD}$, whereas $\mathrm{FA}$ reductions seem to be more relevant for cognitive changes in healthy seniors. On a biological level, it may be assumed that FA values indicate the integrity of axons, whereas MD values rather reflect the integrity of cellular membranes. Consequently, although hypothetical to some extent, cognitive decline in healthy individuals might be driven by the degeneration of axons, whereas AD-related cognitive deterioration may be rather be associated with corrupted cellular membranes.

In the context of functional cerebral changes, AD patients show activation changes particularly in mediotemporal brain regions associated with memory deficits, whereas healthy seniors show activation changes particularly in prefrontal cortex associated with executive dysfunctions. As neural response to increasing task load, AD patients seem to show an upregulation of parietal brain regions, whereas healthy seniors show a frontal upregulation.

Both $\mathrm{AD}$ and normal aging go along with impaired bifrontal and frontoparietal functional connectivity. However, there is evidence for an additional impairment of hippocampal connectivity in $\mathrm{AD}$, whereas 
normal aging is particularly characterized by additionally impaired frontostriatal connections.

Finally, AD is characterized by an accentuated cholinergic dysfunction, whereas normal aging is rather associated with a dopaminergic dysfunction.

Taken together, these qualitative neurocognitive differences between AD and normal aging clearly suggest that $\mathrm{AD}$ cannot be simply regarded as an accelerated aging process. Instead, AD appears to represent a solid entity with specific disease-related changes in cognition, brain structure, and brain function. Future research should specify the different mechanisms of AD pathology and focus on how these processes may be stopped or at least be decelerated. In a clinical context, the qualitative differences described above may help to facilitate single-case diagnostics, e.g., by dissociating normal aging from $\mathrm{AD}$ based upon the identification of a specific deficit profile. A profile including pronounced memory deficits and relatively unimpaired processing speed, for example, may point toward $\mathrm{AD}$, whereas accentuated cognitive slowing together with a mild memory dysfunction would rather be contra indicative. Corresponding deficit profiles may be found for grey or white matter degeneration. In fact, exclusive mediotemporal atrophy argues for $\mathrm{AD}$, whereas frontal atrophy in the absence of mediotemporal atrophy would probably refer to a different pathology.

\section{DISCLOSURE STATEMENT}

The author's disclosure is available online (http://jalz.com/manuscript-disclosures/16-1099r2).

\section{REFERENCES}

[1] Park DC, Lautenschlager G, Hedden T, Davidson NS, Smith AD, Smith PK (2002) Models of visuospatial and verbal memory across the adult life span. Psychol Aging 17, 299-320.

[2] Stanziano DC, Whitehurst M, Graham P, Roos BA (2010) A review of selected longitudinal studies on aging: Past findings and future directions. J Am Geriatr Soc 58(Suppl 2), S292-S297.

[3] Singer T, Verhaeghen P, Ghisletta P, Lindenberger U, Baltes PB (2003) The fate of cognition in very old age: Six-year longitudinal findings in the Berlin Aging Study (BASE). Psychol Aging 18, 318-331.

[4] Bauer E, Toepper M, Gebhardt H, Gallhofer B, Sammer G (2015) The significance of caudate volume for age-related associative memory decline. Brain Res 1622, 137-148.

[5] Buckner RL (2004) Memory and executive function in aging and AD: Multiple factors that cause decline and reserve factors that compensate. Neuron 44, 195-208.
[6] Fjell AM, Walhovd KB (2010) Structural brain changes in aging: Courses, causes and cognitive consequences. Rev Neurosci 21, 187-221.

[7] Hedden T, Gabrieli JD (2004) Insights into the ageing mind A view from cognitive neuroscience. Nat Rev Neurosci 5 , 87-96.

[8] Kennedy KM, Raz N (2009) Aging white matter and cognition: Differential effects of regional variations in diffusion properties on memory, executive functions, and speed. Neuropsychologia 47, 916-927.

[9] O'Sullivan M, Jones DK, Summers PE, Morris RG, Williams SC, Markus HS (2001) Evidence for cortical disconnection as a mechanism of age-related cognitive decline. Neurology 57, 632-638.

[10] Schulze ET, Geary EK, Susmaras TM, Paliga JT, Maki PM, Little DM (2011) Anatomical correlates of agerelated working memory declines. J Aging Res 2011, 606871 .

[11] Zimmerman ME, Brickman AM, Paul RH, Grieve SM, Tate DF, Gunstad J, Cohen RA, Aloia MS, Williams LM, Clark CR, Whitford TJ, Gordon E (2006) The relationship between frontal gray matter volume and cognition varies across the healthy adult lifespan. Am J Geriatr Psychiatry 14, 823-833.

[12] Bosworth HB, Schaie KW (1999) Survival effects in cognitive function, cognitive style, and sociodemographic variables in the Seattle Longitudinal Study. Exp Aging Res 25, 121-139.

[13] Fozard JL, Vercryssen M, Reynolds SL, Hancock PA, Quilter RE (1994) Age differences and changes in reaction time: The Baltimore Longitudinal Study of Aging. J Gerontol 49, P179-P189.

[14] Baddeley A (2000) The episodic buffer: A new component of working memory? Trends Cogn Sci 4, 417-423.

[15] Baddeley A, Della Sala S (1996) Working memory and executive control. Philos Trans $R$ Soc Lond B Biol Sci 351, 1397-1403; discussion 1403-1394.

[16] Baddeley A, Logie RH (1999) Working memory: The multiple component model. In Models of Working Memory, Miyake A, Shah P, eds. Cambrige University Press, New York, pp. 28-61.

[17] Baddeley A, Hitch GJ (1974) Working memory. In Recent advances in learning and motivation, Bower GH, ed. Academic Press, New York, pp. 47-90.

[18] Cowan N (1999) An embedded-process model of working memory. In Models of working memory: Mechanisms of active maintenance and executive control, Miyake A, Shah P, eds. Cambridge University Press, New York, pp. 62-101.

[19] Cushman LA, Stein K, Duffy CJ (2008) Detecting navigational deficits in cognitive aging and Alzheimer disease using virtual reality. Neurology 71, 888-895.

[20] Moffat SD, Elkins W, Resnick SM (2006) Age differences in the neural systems supporting human allocentric spatial navigation. Neurobiol Aging 27, 965-972.

[21] Schaie KW (1996) Intellectual Development in Adulthood: The Seattle Longitudinal Study, Cambridge University Press, Cambridge.

[22] Fleischman DA, Leurgans S, Arfanakis K, Arvanitakis Z, Barnes LL, Boyle PA, Han SD, Bennett DA (2014) Gray-matter macrostructure in cognitively healthy older persons: Associations with age and cognition. Brain Struct Funct 219, 2029-2049.

[23] Good CD, Johnsrude IS, Ashburner J, Henson RN, Friston KJ, Frackowiak RS (2001) A voxel-based morphometric study of ageing in 465 normal adult human brains. Neuroimage 14, 21-36. 
[24] Storsve AB, Fjell AM, Tamnes CK, Westlye LT, Overbye K, Aasland HW, Walhovd KB (2014) Differential longitudinal changes in cortical thickness, surface area and volume across the adult life span: Regions of accelerating and decelerating change. J Neurosci 34, 8488-8498.

[25] Fox NC, Schott JM (2004) Imaging cerebral atrophy: Normal ageing to Alzheimer's disease. Lancet 363, 392-394.

[26] Raz N, Lindenberger U, Rodrigue KM, Kennedy KM, Head D, Williamson A, Dahle C, Gerstorf D, Acker JD (2005) Regional brain changes in aging healthy adults: General trends, individual differences and modifiers. Cereb Cortex 15, 1676-1689.

[27] Scahill RI, Frost C, Jenkins R, Whitwell JL, Rossor MN, Fox NC (2003) A longitudinal study of brain volume changes in normal aging using serial registered magnetic resonance imaging. Arch Neurol 60, 989-994

[28] Di X, Rypma B, Biswal BB (2014) Correspondence of executive function related functional and anatomical alterations in aging brain. Prog Neuropsychopharmacol Biol Psychiatry 48, 41-50.

[29] Fjell AM, Westlye LT, Amlien I, Espeseth T, Reinvang I, Raz N, Agartz I, Salat DH, Greve DN, Fischl B, Dale AM, Walhovd KB (2009) High consistency of regional cortical thinning in aging across multiple samples. Cereb Cortex 19, 2001-2012.

[30] Raz N, Gunning FM, Head D, Dupuis JH, McQuain J, Briggs SD, Loken WJ, Thornton AE, Acker JD (1997) Selective aging of the human cerebral cortex observed in vivo: Differential vulnerability of the prefrontal gray matter. Cereb Cortex 7, 268-282.

[31] Raz N, Rodrigue KM, Kennedy KM, Head D, GunningDixon F, Acker JD (2003) Differential aging of the human striatum: Longitudinal evidence. AJNR Am J Neuroradiol 24, 1849-1856.

[32] Resnick SM, Pham DL, Kraut MA, Zonderman AB, Davatzikos C (2003) Longitudinal magnetic resonance imaging studies of older adults: A shrinking brain. J Neurosci $\mathbf{2 3}, 3295-3301$.

[33] Cardenas VA, Chao LL, Studholme C, Yaffe K, Miller BL, Madison C, Buckley ST, Mungas D, Schuff N, Weiner MW (2011) Brain atrophy associated with baseline and longitudinal measures of cognition. Neurobiol Aging 32, 572-580.

[34] Kaup AR, Mirzakhanian H, Jeste DV, Eyler LT (2011) A review of the brain structure correlates of successful cognitive aging. J Neuropsychiatry Clin Neurosci 23, 6-15.

[35] Tisserand DJ, van Boxtel MP, Pruessner JC, Hofman P, Evans AC, Jolles J (2004) A voxel-based morphometric study to determine individual differences in gray matter density associated with age and cognitive change over time. Cereb Cortex 14, 966-973.

[36] Cabeza R, Nyberg L (2000) Imaging cognition II: An empirical review of 275 PET and fMRI studies. $J$ Cogn Neurosci 12, 1-47.

[37] Goldstein KE, Hazlett EA, Savage KR, Berlin HA, Hamilton HK, Zelmanova Y, Look AE, Koenigsberg HW, Mitsis EM, Tang CY (2011) Dorso-and ventro-lateral prefrontal volume and spatial working memory in schizotypal personality disorder. Behav Brain Res 218, 335-340.

[38] Golomb J, Kluger A, de Leon MJ, Ferris SH, Mittelman M, Cohen J, George AE (1996) Hippocampal formation size predicts declining memory performance in normal aging. Neurology 47, 810-813.

[39] Allen JS, Bruss J, Brown CK, Damasio H (2005) Normal neuroanatomical variation due to age: The major lobes and a parcellation of the temporal region. Neurobiol Aging 26, 1245-1260; discussion 1279-1282.

[40] Fjell AM, Walhovd KB, Reinvang I, Lundervold A, Dale AM, Quinn BT, Makris N, Fischl B (2005) Age does not increase rate of forgetting over weeks - neuroanatomical volumes and visual memory across the adult life-span. $J$ Int Neuropsychol Soc 11, 2-15.

[41] Westlye LT, Walhovd KB, Dale AM, Bjornerud A, DueTonnessen P, Engvig A, Grydeland H, Tamnes CK, Ostby Y, Fjell AM (2010) Life-span changes of the human brain white matter: Diffusion tensor imaging (DTI) and volumetry. Cereb Cortex 20, 2055-2068.

[42] Kochunov P, Williamson DE, Lancaster J, Fox P, Cornell J, Blangero J, Glahn DC (2012) Fractional anisotropy of water diffusion in cerebral white matter across the lifespan. Neurobiol Aging 33, 9-20.

[43] Minati L, Grisoli M, Bruzzone MG (2007) MR spectroscopy, functional MRI, and diffusion-tensor imaging in the aging brain: A conceptual review. J Geriatr Psychiatry Neurol 20, 3-21.

[44] Gunning-Dixon FM, Brickman AM, Cheng JC, Alexopoulos GS (2009) Aging of cerebral white matter: A review of MRI findings. Int J Geriatr Psychiatry 24, 109-117.

[45] Salat DH, Tuch DS, Hevelone ND, Fischl B, Corkin S, Rosas HD, Dale AM (2005) Age-related changes in prefrontal white matter measured by diffusion tensor imaging. Ann N Y Acad Sci 1064, 37-49.

[46] Abe O, Aoki S, Hayashi N, Yamada H, Kunimatsu A, Mori H, Yoshikawa T, Okubo T, Ohtomo K (2002) Normal aging in the central nervous system: Quantitative MR diffusiontensor analysis. Neurobiol Aging 23, 433-441.

[47] Bennett IJ, Madden DJ, Vaidya CJ, Howard DV, Howard $\mathrm{JH} \mathrm{Jr}$ (2010) Age-related differences in multiple measures of white matter integrity: A diffusion tensor imaging study of healthy aging. Hum Brain Mapp 31, 378-390.

[48] Inoue $\mathrm{K}$, Ito $\mathrm{H}$, Uchida S, Taki Y, Kinomura S, Tsuji I, Sato S, Horie K, Kawashima R, Ito M, Fukuda H (2008) Decrease in glucose metabolism in frontal cortex associated with deterioration of microstructure of corpus callosum measured by diffusion tensor imaging in healthy elderly. Hum Brain Mapp 29, 375-384.

[49] Pfefferbaum A, Sullivan EV, Hedehus M, Lim KO, Adalsteinsson E, Moseley M (2000) Age-related decline in brain white matter anisotropy measured with spatially corrected echo-planar diffusion tensor imaging. Magn Reson Med 44, 259-268.

[50] Sullivan EV, Adalsteinsson E, Pfefferbaum A (2006) Selective age-related degradation of anterior callosal fiber bundles quantified in vivo with fiber tracking. Cereb Cortex 16, 1030-1039.

[51] Bennett IJ, Madden DJ (2014) Disconnected aging: Cerebral white matter integrity and age-related differences in cognition. Neuroscience 276, 187-205.

[52] Salat DH (2014) Diffusion tensor imaging in the study of aging and age-associated neural disease. In Diffusion MRI: From quantitative measurement to in vivo neuroanatomy, Johansen-Berg H, Behrens TEJ, eds. Elsevier Academic Press, MA, Cambridge, pp. 257-281.

[53] Sasson E, Doniger GM, Pasternak O, Tarrasch R, Assaf Y (2012) Structural correlates of cognitive domains in normal aging with diffusion tensor imaging. Brain Struct Funct 217, 503-515.

[54] Charlton RA, Barrick TR, Lawes IN, Markus HS, Morris RG (2010) White matter pathways associated with working memory in normal aging. Cortex 46, 474-489. 
[55] Charlton RA, Barrick TR, McIntyre DJ, Shen Y, O'Sullivan M, Howe FA, Clark CA, Morris RG, Markus HS (2006) White matter damage on diffusion tensor imaging correlates with age-related cognitive decline. Neurology 66, 217-222.

[56] Abe O, Yamasue H, Aoki S, Suga M, Yamada H, Kasai K, Masutani Y, Kato N, Kato N, Ohtomo K (2008) Aging in the CNS: Comparison of gray/white matter volume and diffusion tensor data. Neurobiol Aging 29, 102-116.

[57] Rossini PM, Rossi S, Babiloni C, Polich J (2007) Clinical neurophysiology of aging brain: From normal aging to neurodegeneration. Prog Neurobiol 83, 375-400.

[58] Rossini PM, Ferilli MA, Rossini L, Ferreri F (2013) Clinical neurophysiology of brain plasticity in aging brain. Curr Pharm Des 19, 6426-6439.

[59] Grady CL (2008) Cognitive neuroscience of aging. Ann N $Y$ Acad Sci 1124, 127-144.

[60] Guidotti Breting LM, Tuminello ER, Duke Han S (2012) Functional neuroimaging studies in normal aging. Curr Top Behav Neurosci 10, 91-111.

[61] Babiloni C, Babiloni F, Carducci F, Cappa SF, Cincotti F, Del Percio C, Miniussi C, Vito Moretti D, Rossi S, Sosta K, Rossini PM (2004) Human cortical rhythms during visual delayed choice reaction time tasks. A high-resolution EEG study on normal aging. Behav Brain Res 153, 261-271.

[62] Rottschy C, Langner R, Dogan I, Reetz K, Laird AR, Schulz JB, Fox PT, Eickhoff SB (2012) Modelling neural correlates of working memory: A coordinate-based meta-analysis. Neuroimage 60, 830-846.

[63] Davis SW, Dennis NA, Daselaar SM, Fleck MS, Cabeza R (2008) Que PASA? The posterior-anterior shift in aging. Cereb Cortex 18, 1201-1209.

[64] Reuter-Lorenz PA (2002) New visions of the aging mind and brain. Trends Cogn Sci 6, 394.

[65] Cabeza R (2002) Hemispheric asymmetry reduction in older adults: The HAROLD model. Psychol Aging 17, 85-100.

[66] Gutchess AH, Welsh RC, Hedden T, Bangert A, Minear M, Liu LL, Park DC (2005) Aging and the neural correlates of successful picture encoding: Frontal activations compensate for decreased medial-temporal activity. $J \operatorname{Cog} n$ Neurosci 17, 84-96.

[67] Holtzer R, Rakitin BC, Steffener J, Flynn J, Kumar A, Stern Y (2009) Age effects on load-dependent brain activations in working memory for novel material. Brain Res 1249, 148-161.

[68] Johnson MK, Mitchell KJ, Raye CL, Greene EJ (2004) An age-related deficit in prefrontal cortical function associated with refreshing information. Psychol Sci 15, 127-132.

[69] Nagel IE, Preuschhof C, Li SC, Nyberg L, Backman L, Lindenberger U, Heekeren HR (2009) Performance level modulates adult age differences in brain activation during spatial working memory. Proc Natl Acad Sci U S A 106, 22552-22557.

[70] Nagel IE, Preuschhof C, Li SC, Nyberg L, Backman L, Lindenberger U, Heekeren HR (2011) Load modulation of BOLD response and connectivity predicts working memory performance in younger and older adults. $J \operatorname{Cog} n$ Neurosci 23, 2030-2045.

[71] Park DC, Polk TA, Park R, Minear M, Savage A, Smith MR (2004) Aging reduces neural specialization in ventral visual cortex. Proc Natl Acad Sci U S A 101, 13091-13095.

[72] Rajah MN, D'Esposito M (2005) Region-specific changes in prefrontal function with age: A review of PET and fMRI studies on working and episodic memory. Brain 128, 19641983.

[73] Reuter-Lorenz PA, Jonides J, Smith EE, Hartley A, Miller A, Marshuetz C, Koeppe RA (2000) Age differences in the frontal lateralization of verbal and spatial working memory revealed by PET. J Cogn Neurosci 12, 174-187.

[74] Reuter-Lorenz PA, Lustig C (2005) Brain aging: Reorganizing discoveries about the aging mind. Curr Opin Neurobiol 15, 245-251.

[75] Rypma B, Berger JS, D'Esposito M (2002) The influence of working-memory demand and subject performance on prefrontal cortical activity. J Cogn Neurosci 14, 721-731.

[76] Thomsen T, Specht K, Rimol LM, Hammar A, Nyttingnes J, Ersland L, Hugdahl K (2004) Brain localization of attentional control in different age groups by combining functional and structural MRI. Neuroimage 22, 912-919.

[77] Zarahn E, Rakitin B, Abela D, Flynn J, Stern Y (2007) Age-related changes in brain activation during a delayed item recognition task. Neurobiol Aging 28, 784-798.

[78] Bennett IJ, Rypma B (2013) Advances in functional neuroanatomy: A review of combined DTI and fMRI studies in healthy younger and older adults. Neurosci Biobehav Rev 37, 1201-1210.

[79] Reuter-Lorenz PA, Cappell KA (2008) Neurocognitive aging and the compensation hypothesis. Curr Dir Psychol Sci 17, 177-182.

[80] Bennett IJ, Rivera HG, Rypma B (2013) Isolating agegroup differences in working memory load-related neural activity: Assessing the contribution of working memory capacity using a partial-trial fMRI method. Neuroimage 72, 20-32.

[81] Cappell KA, Gmeindl L, Reuter-Lorenz PA (2010) Age differences in prefontal recruitment during verbal working memory maintenance depend on memory load. Cortex 46 , 462-473.

[82] Reuter-Lorenz PA, Park DC (2010) Human neuroscience and the aging mind: A new look at old problems. J Gerontol B Psychol Sci Soc Sci 65, 405-415.

[83] Schneider-Garces NJ, Gordon BA, Brumback-Peltz CR, Shin E, Lee Y, Sutton BP, Maclin EL, Gratton G, Fabiani M (2010) Span, CRUNCH, and beyond: Working memory capacity and the aging brain. J Cogn Neurosci 22, 655-669.

[84] McEvoy LK, Pellouchoud E, Smith ME, Gevins A (2001) Neurophysiological signals of working memory in normal aging. Brain Res Cogn Brain Res 11, 363-376.

[85] Toepper M, Gebhardt H, Bauer E, Haberkamp A, Beblo T, Gallhofer B, Driessen M, Sammer G (2014) The impact of age on load-related dorsolateral prefrontal cortex activation. Front Aging Neurosci 6, 9.

[86] Bauer E, Sammer G, Toepper M (2015) Trying to put the puzzle together: Age and performance level modulate the neural response to increasing task load within left rostral prefrontal cortex. Biomed Res Int 2015, 415458.

[87] Toepper M, Sammer G, Bauer E (2016) Reproducibility of complex fMRI effects. J Am Geriatr Soc 64, e62.

[88] Open Science Collaboration (2015) Psychology. Estimating the reproducibility of psychological science. Science 349, aac4716.

[89] Jolles DD, van Buchem MA, Crone EA, Rombouts SA (2013) Functional brain connectivity at rest changes after working memory training. Hum Brain Mapp 34, 396-406.

[90] Campbell KL, Grady CL, Ng C, Hasher L (2012) Age differences in the frontoparietal cognitive control network: Implications for distractibility. Neuropsychologia 50, 2212-2223. 
[91] Podell JE, Sambataro F, Murty VP, Emery MR, Tong Y, Das S, Goldberg TE, Weinberger DR, Mattay VS (2012) Neurophysiological correlates of age-related changes in working memory updating. Neuroimage 62, 2151-2160.

[92] Steffener J, Habeck CG, Stern Y (2012) Age-related changes in task related functional network connectivity. PLoS One 7, e44421.

[93] Toepper M, Markowitsch HJ, Gebhardt H, Beblo T, Bauer E, Woermann FG, Driessen M, Sammer G (2014) The impact of age on prefrontal cortex integrity during spatial working memory retrieval. Neuropsychologia 59, 157168.

[94] Matthaus F, Schmidt JP, Banerjee A, Schulze TG, Demirakca T, Diener C (2012) Effects of age on the structure of functional connectivity networks during episodic and working memory demand. Brain Connect 2, 113-124.

[95] Sander MC, Lindenberger U, Werkle-Bergner M (2012) Lifespan age differences in working memory: A twocomponent framework. Neurosci Biobehav Rev 36, 2007-2033.

[96] Montembeault M, Joubert S, Doyon J, Carrier J, Gagnon JF, Monchi O, Lungu O, Belleville S, Brambati SM (2012) The impact of aging on gray matter structural covariance networks. Neuroimage 63, 754-759.

[97] Sambataro F, Murty VP, Callicott JH, Tan HY, Das S, Weinberger DR, Mattay VS (2010) Age-related alterations in default mode network: Impact on working memory performance. Neurobiol Aging 31, 839-852.

[98] Stam CJ (2014) Modern network science of neurological disorders. Nat Rev Neurosci 15, 683-695.

[99] Rieckmann A, Karlsson S, Fischer H, Backman L (2011) Caudate dopamine D1 receptor density is associated with individual differences in frontoparietal connectivity during working memory. $J$ Neurosci 31, 14284-14290.

[100] Honey GD, Fu CH, Kim J, Brammer MJ, Croudace TJ, Suckling J, Pich EM, Williams SC, Bullmore ET (2002) Effects of verbal working memory load on corticocortical connectivity modeled by path analysis of functional magnetic resonance imaging data. Neuroimage 17, 573-582.

[101] Narayanan NS, Prabhakaran V, Bunge SA, Christoff K, Fine EM, Gabrieli JD (2005) The role of the prefrontal cortex in the maintenance of verbal working memory: An event-related FMRI analysis. Neuropsychology 19, 223232.

[102] López ME, Garcés P, Cuesta P, Castellanos NP, Aurtenetxe S, Bajo R, Marcos A, Montenegro M, Yubero R, del Pozo F (2014) Synchronization during an internally directed cognitive state in healthy aging and mild cognitive impairment: A MEG study. Age 36, 1389-1406.

[103] Bäckman L, Nyberg L, Lindenberger U, Li SC, Farde L (2006) The correlative triad among aging, dopamine, and cognition: Current status and future prospects. Neurosci Biobehav Rev 30, 791-807.

[104] Li S-C, Lindenberger U, Bäckman L (2010) Dopaminergic modulation of cognition across the life span. Neurosci Biobehav Rev 34, 625-630.

[105] Landau SM, Lal R, O’Neil JP, Baker S, Jagust WJ (2009) Striatal dopamine and working memory. Cereb Cortex 19, 445-454.

[106] D'Esposito M, Postle BR, Ballard D, Lease J (1999) Maintenance versus manipulation of information held in working memory: An event-related fMRI study. Brain Cogn 41, 66-86.

[107] Owen AM (1997) The functional organization of working memory processes within human lateral frontal cortex:
The contribution of functional neuroimaging. Eur J Neurosci $9,1329-1339$.

[108] Owen AM, Evans AC, Petrides M (1996) Evidence for a two-stage model of spatial working memory processing within the lateral frontal cortex: A positron emission tomography study. Cereb Cortex 6, 31-38.

[109] Owen AM, Herrod NJ, Menon DK, Clark JC, Downey SP, Carpenter TA, Minhas PS, Turkheimer FE, Williams EJ, Robbins TW, Sahakian BJ, Petrides M, Pickard JD (1999) Redefining the functional organization of working memory processes within human lateral prefrontal cortex. Eur J Neurosci 11, 567-574.

[110] Petrides M (1995) Functional organization of the human frontal cortex for mnemonic processing. Evidence from neuroimaging studies. Ann N Y Acad Sci 769, 85-96.

[111] Wagner AD, Maril A, Bjork RA, Schacter DL (2001) Prefrontal contributions to executive control: FMRI evidence for functional distinctions within lateral Prefrontal cortex. Neuroimage 14, 1337-1347.

[112] Badre D, D'Esposito M (2009) Is the rostro-caudal axis of the frontal lobe hierarchical? Nat Rev Neurosci 10, 659669.

[113] Blumenfeld RS, Nomura EM, Gratton C, D’Esposito M (2013) Lateral prefrontal cortex is organized into parallel dorsal and ventral streams along the rostro-caudal axis. Cereb Cortex 23, 2457-2466.

[114] Courtney SM, Petit L, Maisog JM, Ungerleider LG, Haxby JV (1998) An area specialized for spatial working memory in human frontal cortex. Science 279, 1347-1351.

[115] Nee DE, Brown JW (2012) Rostral-caudal gradients of abstraction revealed by multi-variate pattern analysis of working memory. Neuroimage 63, 1285-1294.

[116] Rypma B, D'Esposito M (2000) Isolating the neural mechanisms of age-related changes in human working memory. Nat Neurosci 3, 509-515.

[117] Rypma B, Prabhakaran V, Desmond JE, Gabrieli JD (2001) Age differences in prefrontal cortical activity in working memory. Psychol Aging 16, 371-384.

[118] Persson J, Nyberg L, Lind J, Larsson A, Nilsson L-G, Ingvar M, Buckner RL (2006) Structure-function correlates of cognitive decline in aging. Cereb Cortex 16, 907-915.

[119] Jack CR Jr, Knopman DS, Jagust WJ, Petersen RC, Weiner MW, Aisen PS, Shaw LM, Vemuri P, Wiste HJ, Weigand SD, Lesnick TG, Pankratz VS, Donohue MC, Trojanowski JQ (2013) Tracking pathophysiological processes in Alzheimer's disease: An updated hypothetical model of dynamic biomarkers. Lancet Neurol 12, 207-216.

[120] Jack CR Jr, Knopman DS, Jagust WJ, Shaw LM, Aisen PS, Weiner MW, Petersen RC, Trojanowski JQ (2010) Hypothetical model of dynamic biomarkers of the Alzheimer's pathological cascade. Lancet Neurol 9, 119-128.

[121] Kurz A (2002) Klinik. In Demenzen, eds. Beyreuther K, Einhäuple H, Förstl H, Kurz A, eds. Georg Thieme Verlag, Stuttgart, pp. 168-186.

[122] Braak H, Braak E (2002) Neuroanatomie. In Demenzen, Beyreuther K, Einhäuple H, Förstl H, Kurz A, eds. Georg Thieme Verlag, Stuttgart, pp. 118-129.

[123] Braak H, Del Tredici K (2015) Neuroanatomy and Pathology of Sporadic Alzheimer's Disease, Springer International Publishing.

[124] Goedert M (2015) Neurodegeneration. Alzheimer's and Parkinson's diseases: The prion concept in relation to assembled $\mathrm{A} \beta$, tau, and $\alpha$-synuclein. Science 349, 1255555. 
[125] Choi SH, Kim YH, Hebisch M, Sliwinski C, Lee S, D'Avanzo C, Chen H, Hooli B, Asselin C, Muffat J, Klee JB, Zhang C, Wainger BJ, Peitz M, Kovacs DM, Woolf CJ, Wagner SL, Tanzi RE, Kim DY (2014) A three-dimensional human neural cell culture model of Alzheimer's disease. Nature 515, 274-278.

[126] Hardy JA, Higgins GA (1992) Alzheimer's disease: The amyloid cascade hypothesis. Science 256, 184.

[127] Querfurth HW, LaFerla FM (2010) Alzheimer's disease. $N$ Engl J Med 362, 329-344.

[128] Teipel SJ, Meindl T, Grinberg L, Grothe M, Cantero JL, Reiser MF, Möller HJ, Heinsen H, Hampel H (2011) The cholinergic system in mild cognitive impairment and Alzheimer's disease: An in vivo MRI and DTI study. Hum Brain Mapp 32, 1349-1362.

[129] Fagan AM, Mintun MA, Mach RH, Lee SY, Dence CS, Shah AR, LaRossa GN, Spinner ML, Klunk WE, Mathis CA, DeKosky ST, Morris JC, Holtzman DM (2006) Inverse relation between in vivo amyloid imaging load and cerebrospinal fluid Abeta42 in humans. Ann Neurol 59, 512-519.

[130] Fagan AM, Mintun MA, Shah AR, Aldea P, Roe CM, Mach RH, Marcus D, Morris JC, Holtzman DM (2009) Cerebrospinal fluid tau and ptau(181) increase with cortical amyloid deposition in cognitively normal individuals: Implications for future clinical trials of Alzheimer's disease. EMBO Mol Med 1, 371-380.

[131] Seppälä TT, Nerg O, Koivisto AM, Rummukainen J, Puli L, Zetterberg H, Pyykkö OT, Helisalmi S, Alafuzoff I, Hiltunen M, Jääskeläinen JE, Rinne J, Soininen H, Leinonen V, Herukka SK (2012) CSF biomarkers for Alzheimer disease correlate with cortical brain biopsy findings. Neurology 78, 1568-1575.

[132] Buerger K, Ewers M, Pirttila T, Zinkowski R, Alafuzoff I, Teipel SJ, DeBernardis J, Kerkman D, McCulloch C, Soininen H, Hampel H (2006) CSF phosphorylated tau protein correlates with neocortical neurofibrillary pathology in Alzheimer's disease. Brain 129, 3035-3041.

[133] Tapiola T, Alafuzoff I, Herukka SK, Parkkinen L, Hartikainen P, Soininen H, Pirttilä T (2009) Cerebrospinal fluid beta-amyloid 42 and tau proteins as biomarkers of Alzheimer-type pathologic changes in the brain. Arch Neurol 66, 382-389.

[134] Hampel H, Blennow K, Shaw LM, Hoessler YC, Zetterberg H, Trojanowski JQ (2010) Total and phosphorylated tau protein as biological markers of Alzheimer's disease. Exp Gerontol 45, 30-40.

[135] Blennow K (2004) Cerebrospinal fluid protein biomarkers for Alzheimer's disease. NeuroRx 1, 213-225.

[136] Hertze J, Minthon L, Zetterberg H, Vanmechelen E, Blennow K, Hansson O (2010) Evaluation of CSF biomarkers as predictors of Alzheimer's disease: A clinical follow-up study of 4.7 years. J Alzheimers Dis 21, 1119-1128.

[137] Sunderland T, Linker G, Mirza N, Putnam KT, Friedman DL, Kimmel LH, Bergeson J, Manetti GJ, Zimmermann M, Tang B, Bartko JJ, Cohen RM (2003) Decreased betaamyloid1-42 and increased tau levels in cerebrospinal fluid of patients with Alzheimer disease. JAMA 289, 2094-2103.

[138] Guhra M, Thomas C, Boedeker S, Kreisel S, Driessen M, Beblo T, Ohrmann P, Toepper M (2016) Linking CSF and cognition in Alzheimer's disease: Reanalysis of clinical data. Exp Gerontol 73, 107-113.

[139] Hansson O, Zetterberg H, Buchhave P, Londos E, Blennow K, Minthon L (2006) Association between CSF biomark- ers and incipient Alzheimer's disease in patients with mild cognitive impairment: A follow-up study. Lancet Neurol 5, 228-234.

[140] Okonkwo OC, Mielke MM, Griffith HR, Moghekar AR, O'Brien RJ, Shaw LM, Trojanowski JQ, Albert MS (2011) Cerebrospinal fluid profiles and prospective course and outcome in patients with amnestic mild cognitive impairment. Arch Neurol 68, 113-119.

[141] Arrighi HM, Gelinas I, McLaughlin TP, Buchanan J, Gauthier S (2013) Longitudinal changes in functional disability in Alzheimer's disease patients. Int Psychogeriatr 25, 929-937.

[142] Dubois B, Feldman HH, Jacova C, Cummings JL, Dekosky ST, Barberger-Gateau P, Delacourte A, Frisoni G, Fox NC, Galasko D, Gauthier S, Hampel H, Jicha GA, Meguro K, O’Brien J, Pasquier F, Robert P, Rossor M, Salloway S, Sarazin M, de Souza LC, Stern Y, Visser PJ, Scheltens P (2010) Revising the definition of Alzheimer's disease: A new lexicon. Lancet Neurol 9, 1118-1127.

[143] Dubois B, Feldman HH, Jacova C, Dekosky ST, Barberger-Gateau P, Cummings J, Delacourte A, Galasko D, Gauthier S, Jicha G, Meguro K, O’Brien J, Pasquier F, Robert P, Rossor M, Salloway S, Stern Y, Visser PJ, Scheltens P (2007) Research criteria for the diagnosis of Alzheimer's disease: Revising the NINCDS-ADRDA criteria. Lancet Neurol 6, 734-746.

[144] Budson AE, Michalska KJ, Rentz DM, Joubert CC, Daffner KR, Schacter DL, Sperling RA (2002) Use of a false recognition paradigm in an Alzheimer's disease clinical trial: A pilot study. Am J Alzheimers Dis Other Demen 17, 93-100.

[145] Budson AE, Sullivan AL, Mayer E, Daffner KR, Black PM, Schacter DL (2002) Suppression of false recognition in Alzheimer's disease and in patients with frontal lobe lesions. Brain 125, 2750-2765.

[146] Chapman RM, Mapstone M, McCrary JW, Gardner MN, Porsteinsson A, Sandoval TC, Guillily MD, Degrush E, Reilly LA (2011) Predicting conversion from mild cognitive impairment to Alzheimer's disease using neuropsychological tests and multivariate methods. J Clin Exp Neuropsychol 33, 187-199.

[147] Schacter DL, Slotnick SD (2004) The cognitive neuroscience of memory distortion. Neuron 44, 149-160.

[148] Wolk DA, Signoff ED, Dekosky ST (2008) Recollection and familiarity in amnestic mild cognitive impairment: A global decline in recognition memory. Neuropsychologia 46, 1965-1978.

[149] Verma M, Howard RJ (2012) Semantic memory and language dysfunction in early Alzheimer's disease: A review. Int J Geriatr Psychiatry 27, 1209-1217.

[150] Henderson VW, Mack W, Freed DM, Kempler D, Andersen ES (1990) Naming consistency in Alzheimer's disease. Brain Lang 39, 530-538.

[151] Di Giacomo D, De Federicis LS, Pistelli M, Fiorenzi D, Sodani E, Carbone G, Passafiume D (2012) The loss of conceptual associations in mild Alzheimer's dementia. J Clin Exp Neuropsychol 34, 643-653.

[152] Martin A, Fedio P (1983) Word production and comprehension in Alzheimer's disease: The breakdown of semantic knowledge. Brain Lang 19, 124-141.

[153] Passafiume D, De Federicis LS, Carbone G, Di Giacomo D (2012) Loss of semantic associative categories in patients with Alzheimer's disease. Appl Neuropsychol Adult 19, 305-311. 
[154] Toepper M, Boedeker S, Bauer E, Westphal S, Driessen M, Beblo T (2014) Does Mount Vesuvius indicate an outbreak of Alzheimer's disease? J Am Geriatr Soc 62, 1989-1991.

[155] Kaplan E, Goodglass H, Weintraub S (1983) The Boston Naming Test, Lea \& Febiger, Philadelphia.

[156] Iachini I, Iavarone A, Senese VP, Ruotolo F, Ruggiero G (2009) Visuospatial memory in healthy elderly, AD and MCI: A review. Curr Aging Sci 2, 43-59.

[157] Baeckman L, Jones S, Berger AK, Laukka EJ, Small BJ (2005) Cognitive impairment in preclinical Alzheimer's disease: A meta-analysis. Neuropsychology 19, 520-531.

[158] Baudic S, Barba GD, Thibaudet MC, Smagghe A, Remy P, Traykov L (2006) Executive function deficits in early Alzheimer's disease and their relations with episodic memory. Arch Clin Neuropsychol 21, 15-21.

[159] Chen P, Ratcliff G, Belle SH, Cauley JA, DeKosky ST, Ganguli M (2001) Patterns of cognitive decline in presymptomatic Alzheimer disease: A prospective community study. Arch Gen Psychiatry 58, 853-858.

[160] Collie A, Maruff P (2000) The neuropsychology of preclinical Alzheimer's disease and mild cognitive impairment. Neurosci Biobehav Rev 24, 365-374.

[161] Salmon DP (2012) Neuropsychological features of mild cognitive impairment and preclinical Alzheimer's disease. Curr Top Behav Neurosci 10, 187-212.

[162] Clark LR, Schiehser DM, Weissberger GH, Salmon DP, Delis DC, Bondi MW (2012) Specific measures of executive function predict cognitive decline in older adults. J Int Neuropsychol Soc 18, 118-127.

[163] Gibbons LE, Carle AC, Mackin RS, Harvey D, Mukherjee S, Insel P, Curtis SM, Mungas D, Crane PK (2012) A composite score for executive functioning, validated in Alzheimer's Disease Neuroimaging Initiative (ADNI) participants with baseline mild cognitive impairment. Brain Imaging Behav 6, 517-527.

[164] Toepper M, Beblo T, Thomas C, Driessen M (2008) Early detection of Alzheimer's disease: A new working memory paradigm. Int J Geriatr Psychiatry 23, 272-278.

[165] Toepper M, Beblo T, Beckmann N, Gebhardt H, Thomas C, Driessen M, Sammer G (2013) The block suppression test uncovers specific inhibitory deficits in mild cognitive impairment. Int J Geriatr Psychiatry 28, 769-770.

[166] Association As (2013) Alzheimer's disease facts and figures. Alzheimers Dement 9, 208-245.

[167] Toepper M, Steuwe C, Beblo T, Bauer E, Boedeker S, Thomas C, Markowitsch HJ, Driessen M, Sammer G (2014) Deficient symbol processing in Alzheimer disease. Alzheimer Dis Assoc Disord 28, 340-346.

[168] Ott BR, Heindel WC, Papandonatos GD, Festa EK, Davis JD, Daiello LA, Morris JC (2008) A longitudinal study of drivers with Alzheimer disease. Neurology 70, 1171-1178.

[169] Stern RG, Mohs RC, Davidson M, Schmeidler J, Silverman J, Kramer-Ginsberg E, Searcey T, Bierer L, Davis KL (1994) A longitudinal study of Alzheimer's disease: Measurement, rate, and predictors of cognitive deterioration. Am J Psychiatry 151, 390-396.

[170] Suh GH, Ju YS, Yeon BK, Shah A (2004) A longitudinal study of Alzheimer's disease: Rates of cognitive and functional decline. Int J Geriatr Psychiatry 19, 817-824.

[171] Bozoki AC, An H, Bozoki ES, Little RJ (2009) The existence of cognitive plateaus in Alzheimer's disease. Alzheimers Dement 5, 470-478.

[172] Yang J, Pan P, Song W, Huang R, Li J, Chen K, Gong Q, Zhong J, Shi H, Shang H (2012) Voxelwise meta-analysis of gray matter anomalies in Alzheimer's disease and mild cognitive impairment using anatomic likelihood estimation. J Neurol Sci 316, 21-29.

[173] De Leon M, DeSanti S, Zinkowski R, Mehta P, Pratico D, Segal S, Clark C, Kerkman D, DeBernardis J, Li J (2004) MRI and CSF studies in the early diagnosis of Alzheimer's disease. J Intern Med 256, 205-223.

[174] Ferreira LK, Diniz BS, Forlenza OV, Busatto GF, Zanetti MV (2011) Neurostructural predictors of Alzheimer's disease: A meta-analysis of VBM studies. Neurobiol Aging 32, 1733-1741.

[175] Sexton CE, Mackay CE, Lonie JA, Bastin ME, Terrière E, O'Carroll RE, Ebmeier KP (2010) MRI correlates of episodic memory in Alzheimer's disease, mild cognitive impairment, and healthy aging. Psychiatry Res 184, 57-62.

[176] Canu E, McLaren DG, Fitzgerald ME, Bendlin BB, Zoccatelli G, Alessandrini F, Pizzini FB, Ricciardi GK, Beltramello A, Johnson SC, Frisoni GB (2010) Microstructural diffusion changes are independent of macrostructural volume loss in moderate to severe Alzheimer's disease. J Alzheimers Dis 19, 963-976.

[177] Teipel SJ, Meindl T, Wagner M, Stieltjes B, Reuter S, Hauenstein K-H, Filippi M, Ernemann U, Reiser MF, Hampel H (2010) Longitudinal changes in fiber tract integrity in healthy aging and mild cognitive impairment: A DTI follow-up study. J Alzheimers Dis 22, 507-522.

[178] McDonald CR, McEvoy LK, Gharapetian L, FennemaNotestine C, Hagler DJ Jr, Holland D, Koyama A, Brewer JB, Dale AM, Alzheimer's Disease Neuroimaging Initiative (2009) Regional rates of neocortical atrophy from normal aging to early Alzheimer disease. Neurology 73, 457-465.

[179] Busatto GF, Diniz BS, Zanetti MV (2008) Voxel-based morphometry in Alzheimer's disease. Expert Rev Neurother 8, 1691-1702.

[180] Head D, Snyder AZ, Girton LE, Morris JC, Buckner RL (2005) Frontal-hippocampal double dissociation between normal aging and Alzheimer's disease. Cereb Cortex 15, 732-739.

[181] Jack CR Jr, Lowe VJ, Senjem ML, Weigand SD, Kemp BJ, Shiung MM, Knopman DS, Boeve BF, Klunk WE, Mathis CA, Petersen RC (2008) 11C PiB and structural MRI provide complementary information in imaging of Alzheimer's disease and amnestic mild cognitive impairment. Brain 131, 665-680.

[182] Li JP, Pan P, Huang R, Shang H (2012) A meta-analysis of voxel-based morphometry studies of white matter volume alterations in Alzheimer's disease. Neurosci Biobehav Rev 36, 757-763.

[183] Salat DH, Greve DN, Pacheco JL, Quinn BT, Helmer KG, Buckner RL, Fischl B (2009) Regional white matter volume differences in nondemented aging and Alzheimer's disease. Neuroimage 44, 1247-1258.

[184] Minati L, Edginton T, Bruzzone MG, Giaccone G (2009) Reviews: Current concepts in Alzheimer's disease: A multidisciplinary review. Am J Alzheimers Dis Other Demen 24, 95-121.

[185] Teipel SJ, Stahl R, Dietrich O, Schoenberg SO, Perneczky R, Bokde AL, Reiser MF, Möller H-J, Hampel H (2007) Multivariate network analysis of fiber tract integrity in Alzheimer's disease. Neuroimage 34, 985-995.

[186] Ewers M, Frisoni GB, Teipel SJ, Grinberg LT, Amaro E, Heinsen H, Thompson PM, Hampel H (2011) Staging Alzheimer's disease progression with multimodality neuroimaging. Prog Neurobiol 95, 535-546. 
[187] Salat DH, Tuch DS, van der Kouwe AJW, Greve DN, Pappu V, Lee SY, Hevelone ND, Zaleta AK, Growdon JH, Corkin S (2010) White matter pathology isolates the hippocampal formation in Alzheimer's disease. Neurobiol Aging 31, 244-256.

[188] Stebbins G, Murphy C (2009) Diffusion tensor imaging in Alzheimer's disease and mild cognitive impairment. Behav Neurol 21, 39-49.

[189] Duan J-H, Wang H-Q, Xu J, Lin X, Chen S-Q, Kang Z, Yao Z-B (2006) White matter damage of patients with Alzheimer's disease correlated with the decreased cognitive function. Surg Radiol Anat 28, 150-156.

[190] Damoiseaux JS, Smith SM, Witter MP, Sanz-Arigita EJ, Barkhof F, Scheltens P, Stam CJ, Zarei M, Rombouts SA (2009) White matter tract integrity in aging and Alzheimer's disease. Hum Brain Mapp 30, 1051-1059.

[191] Xie S, Xiao J, Gong G, Zang Y, Wang Y, Wu H, Jiang X (2006) Voxel-based detection of white matter abnormalities in mild Alzheimer disease. Neurology 66, 1845-1849.

[192] Head D, Buckner RL, Shimony JS, Williams LE, Akbudak E, Conturo TE, McAvoy M, Morris JC, Snyder AZ (2004) Differential vulnerability of anterior white matter in nondemented aging with minimal acceleration in dementia of the Alzheimer type: Evidence from diffusion tensor imaging. Cereb Cortex 14, 410-423.

[193] Oishi K, Mielke MM, Albert M, Lyketsos CG, Mori S (2011) DTI analyses and clinical applications in Alzheimer's disease. J Alzheimers Dis 26, 287-296.

[194] Rémy F, Vayssière N, Saint-Aubert L, Barbeau E, Pariente J (2015) White matter disruption at the prodromal stage of Alzheimer's disease: Relationships with hippocampal atrophy and episodic memory performance. Neuroimage 7, 482-492.

[195] Radanovic M, Pereira FRS, Stella F, Aprahamian I, Ferreira LK, Forlenza OV, Busatto GF (2013) White matter abnormalities associated with Alzheimer's disease and mild cognitive impairment: A critical review of MRI studies. Expert Rev Neurother 13, 483-493.

[196] Villain N, Desgranges B, Viader F, De La Sayette V, Mézenge F, Landeau B, Baron J-C, Eustache F, Chételat G (2008) Relationships between hippocampal atrophy, white matter disruption, and gray matter hypometabolism in Alzheimer's disease. J Neurosci 28, 6174-6181.

[197] Karrasch M, Laine M, Rinne JO, Rapinoja P, Sinerva E, Krause CM (2006) Brain oscillatory responses to an auditory-verbal working memory task in mild cognitive impairment and Alzheimer's disease. Int J Psychophysiol 59, $168-178$.

[198] Missonnier P, Gold G, Herrmann FR, Fazio-Costa L, Michel JP, Deiber MP, Michon A, Giannakopoulos P (2006) Decreased theta event-related synchronization during working memory activation is associated with progressive mild cognitive impairment. Dement Geriatr Cogn Disord 22, 250-259.

[199] van der Hiele K, Vein AA, Kramer CG, Reijntjes RH, van Buchem MA, Westendorp RG, Bollen EL, van Dijk JG, Middelkoop HA (2007) Memory activation enhances EEG abnormality in mild cognitive impairment. Neurobiol Aging 28, 85-90.

[200] van der Hiele K, Vein AA, van der Welle A, van der Grond J, Westendorp RG, Bollen EL, van Buchem MA, van Dijk JG, Middelkoop HA (2007) EEG and MRI correlates of mild cognitive impairment and Alzheimer's disease. Neurobiol Aging 28, 1322-1329.
[201] Sperling R (2007) Functional MRI studies of associative encoding in normal aging, mild cognitive impairment, and Alzheimer's disease. Ann N Y Acad Sci 1097, 146-155.

[202] Sperling R (2011) The potential of functional MRI as a biomarker in early Alzheimer's disease. Neurobiol Aging 32, 37-43.

[203] Dickerson BC, Sperling RA (2008) Functional abnormalities of the medial temporal lobe memory system in mild cognitive impairment and Alzheimer's disease: Insights from functional MRI studies. Neuropsychologia 46, 16241635.

[204] Chhatwal JP, Sperling RA (2012) Functional MRI of mnemonic networks across the spectrum of normal aging, mild cognitive impairment, and Alzheimer's disease. J Alzheimers Dis 31, S155-S167.

[205] Grady CL, McIntosh AR, Beig S, Keightley ML, Burian H, Black SE (2003) Evidence from functional neuroimaging of a compensatory prefrontal network in Alzheimer's disease. J Neurosci 23, 986-993.

[206] Peters F, Collette F, Degueldre C, Sterpenich V, Majerus S, Salmon E (2009) The neural correlates of verbal short-term memory in Alzheimer's disease: An fMRI study. Brain 132, 1833-1846.

[207] Bokde AL, Karmann M, Born C, Teipel SJ, Omerovic M, Ewers M, Frodl T, Meisenzahl E, Reiser M, Möller H-J (2010) Altered brain activation during a verbal working memory task in subjects with amnestic mild cognitive impairment. J Alzheimers Dis 21, 103-118.

[208] Rosano C, Aizenstein HJ, Cochran JL, Saxton JA, De Kosky ST, Newman AB, Kuller LH, Lopez OL, Carter CS (2005) Event-related functional magnetic resonance imaging investigation of executive control in very old individuals with mild cognitive impairment. Biol Psychiatry 57, 761-767.

[209] Yetkin FZ, Rosenberg RN, Weiner MF, Purdy PD, Cullum CM (2006) FMRI of working memory in patients with mild cognitive impairment and probable Alzheimer's disease. Eur Radiol 16, 193-206.

[210] Lim H-K, Juh R, Pae C-U, Lee B-T, Yoo S-S, Ryu S-H, Kwak K-R, Lee C, Lee C-U (2008) Altered verbal working memory process in patients with Alzheimer's disease. Neuropsychobiology 57, 181-187.

[211] Van Dam NT, Sano M, Mitsis EM, Grossman HT, Gu X, Park Y, Hof PR, Fan J (2013) Functional neural correlates of attentional deficits in amnestic mild cognitive impairment. PloS One 8, e54035.

[212] Sorg C, Riedl V, Perneczky R, Kurz A, Wohlschlager AM (2009) Impact of Alzheimer's disease on the functional connectivity of spontaneous brain activity. Curr Alzheimer Res 6, 541-553.

[213] Bassett DS, Bullmore ET (2009) Human brain networks in health and disease. Curr Opin Neurol 22, 340-347.

[214] Xie T, He Y (2012) Mapping the Alzheimer's brain with connectomics. Front Psychiatry 2, 77.

[215] Pijnenburg YA, v d Made Y, van Cappellen van Walsum AM, Knol DL, Scheltens P, Stam CJ (2004) EEG synchronization likelihood in mild cognitive impairment and Alzheimer's disease during a working memory task. Clin Neurophysiol 115, 1332-1339.

[216] de Haan W, Mott K, van Straaten EC, Scheltens P, Stam CJ (2012) Activity dependent degeneration explains hub vulnerability in Alzheimer's disease. PLoS Comput Biol 8, e1002582.

[217] de Haan W, van der Flier WM, Wang H, van Mieghem PF, Scheltens P, Stam CJ (2012) Disruption of functional 
brain networks in Alzheimer's disease: What can we learn from graph spectral analysis of resting-state magnetoencephalography? Brain Connect 2, 45-55.

[218] Fornito A, Zalesky A, Breakspear M (2015) The connectomics of brain disorders. Nat Rev Neurosci 16, 159-172.

[219] Agosta F, Pievani M, Geroldi C, Copetti M, Frisoni GB, Filippi M (2012) Resting state fMRI in Alzheimer's disease: Beyond the default mode network. Neurobiol Aging 33, 1564-1578.

[220] Dennis EL, Thompson PM (2014) Functional brain connectivity using fMRI in aging and Alzheimer's disease. Neuropsychol Rev 24, 49-62.

[221] Zhou Y, Dougherty JH, Hubner KF, Bai B, Cannon RL, Hutson RK (2008) Abnormal connectivity in the posterior cingulate and hippocampus in early Alzheimer's disease and mild cognitive impairment. Alzheimers Dement 4, 265-270.

[222] Joo SH, Lim HK, Lee CU (2016) Three large-scale functional brain networks from resting-state functional MRI in subjects with different levels of cognitive impairment. Psychiatry Investig 13, 1-7.

[223] Sorg C, Riedl V, Mühlau M, Calhoun VD, Eichele T, Läer L, Drzezga A, Förstl H, Kurz A, Zimmer C (2007) Selective changes of resting-state networks in individuals at risk for Alzheimer's disease. Proc Natl Acad Sci U S A 104, 18760-18765.

[224] Jiang ZY, Zheng LL (2006) Inter- and intra-hemispheric EEG coherence in patients with mild cognitive impairment at rest and during working memory task. J Zhejiang Univ Sci B 7, 357-364.

[225] Terry AV Jr, Buccafusco JJ (2003) The cholinergic hypothesis of age and Alzheimer's disease-related cognitive deficits: Recent challenges and their implications for novel drug development. J Pharmacol Exp Ther 306, 821-827.

[226] Ferreira-Vieira TH, Guimaraes IM, Silva FR, Ribeiro FM (2016) Alzheimer's disease: Targeting the Cholinergic System. Curr Neuropharmacol 14, 101-115.

[227] Teipel SJ, Flatz WH, Heinsen H, Bokde AL, Schoenberg SO, Stöckel S, Dietrich O, Reiser MF, Möller H-J, Hampel H (2005) Measurement of basal forebrain atrophy in Alzheimer's disease using MRI. Brain 128, 2626-2644.

[228] Blennow K, de Leon MJ, Zetterberg H (2006) Alzheimer's disease. Lancet 368, 387-403.
[229] Kumar A, Singh A, Ekavali E (2015) A review on Alzheimer's disease pathophysiology and its management: An update. Pharmacol Rep 67, 195-203.

[230] Scheltens P, Blennow K, Breteler MM, de Strooper B, Frisoni GB, Salloway S, Van der Flier WM (2016) Alzheimer's disease. Lancet 388, 505-517.

[231] Fernandez A, Arrazola J, Maestu F, Amo C, Gil-Gregorio P, Wienbruch C, Ortiz T (2003) Correlations of hippocampal atrophy and focal low-frequency magnetic activity in Alzheimer disease: Volumetric MR imagingmagnetoencephalographic study. AJNR Am J Neuroradiol 24, 481-487.

[232] Helkala EL, Hanninen T, Hallikainen M, Kononen M, Laakso MP, Hartikainen P, Soininen H, Partanen J, Partanen K, Vainio P, Riekkinen P, Sr (1996) Slow-wave activity in the spectral analysis of the electroencephalogram and volumes of hippocampus in subgroups of Alzheimer's disease patients. Behav Neurosci 110, 1235-1243.

[233] Amlien I, Fjell A (2014) Diffusion tensor imaging of white matter degeneration in Alzheimer's disease and mild cognitive impairment. Neuroscience 276, 206-215.

[234] Bendlin BB, Carlsson CM, Johnson SC, Zetterberg H, Blennow K, Willette AA, Okonkwo OC, Sodhi A, Ries ML, Birdsill AC, Alexander AL, Rowley HA, Puglielli L, Asthana S, Sager MA (2012) CSF T-Tau/A $\beta 42$ predicts white matter microstructure in healthy adults at risk for Alzheimer's disease. PLoS One 7, e37720.

[235] Putcha D, Brickhouse M, O'Keefe K, Sullivan C, Rentz D, Marshall G, Dickerson B, Sperling R (2011) Hippocampal hyperactivation associated with cortical thinning in Alzheimer's disease signature regions in non-demented elderly adults. $J$ Neurosci 31, 17680-17688.

[236] Huijbers W, Mormino EC, Schultz AP, Wigman S, Ward AM, Larvie M, Amariglio RE, Marshall GA, Rentz DM, Johnson KA, Sperling RA (2015) Amyloid-beta deposition in mild cognitive impairment is associated with increased hippocampal activity, atrophy and clinical progression. Brain 138, 1023-1035. 